\title{
Reforma agraria y violencia campesina en Catemaco, Veracruz (México), 1921-1958*
}

\section{Resumen}

El objetivo de este artículo es mostrar las gestiones que los campesinos de Catemaco, Veracruz, una de las poblaciones que conformaban el Cantón de los Tuxtlas, hicieron ante las autoridades agrarias para tratar de obtener tierras. El proceso resultó sumamente conflictivo como consecuencia de diversos hechos: el conflicto que se generó entre dos grupos de campesinos, desde el mismo inicio del proceso, por obtener la dirección del comité agrario; las alianzas que los dos grupos establecieron con actores políticos como el Ayuntamiento, la guerrilla agraria y las autoridades estatales y nacionales, alianzas que contribuyeron a modificar el balance de poder; y los actos en los que estuvo involucrado un ingeniero de la Comisión Nacional Agraria, destacado en la población, mismos que provocarían un enfrentamiento armado entre los ejidatarios de Catemaco y de Maxacapan. La conflictiva situación entre las dos poblaciones tendría una resolución inesperada: la disgregación de una porción del territorio catemaquense.

Palabras clave: Catemaco, Los Tuxtlas, Maxacapan, reforma agraria, sindicato, campesinos.

Referencia para citar este artículo: JIMÉNEZ MARCE, Rogelio (2015). "Reforma agraria y violencia campesina en Catemaco, Veracruz (México), 1921-1958". En Anuario de Historia Regional y de las Fronteras. 20 (2). pp. 71-99.

Rogelio Jiménez Marce: Doctor en antropología del Centro de Investigaciones y Estudios Superiores en Antropología Social, CIESAS. Maestro en Historia por el Instituto Mora. Licenciado en Historia por la Benemérita Universidad de Puebla, BUAP. Profesor Investigador de tiempo completo del Instituto de Ciencias Sociales y Humanidades, BUAP. Correo electrónico: rojimarc@yahoo.com.mx.

\footnotetext{
*Artículo de investigación realizado en el marco de la estancia de retención en el ICSyH de la Benemérita Universidad Autónoma de Puebla. Agradezco a la maestra Olivia Domínguez, directora del Archivo General del Estado de Veracruz por las facilidades para consultar los materiales que sirven de base a este trabajo, así como su autorización para reproducir los mapas que se incluyen en el mismo.
} 


\title{
Agricultural reformation and rural violence in Catemaco, Veracruz (Mexico), 1921-1958
}

\begin{abstract}
The objective of the article is showing the management that the farmers from Catemaco, Veracruz, one of the towns that comprised the Province of Tuxtlas, made before the agricultural authorities in order to obtain lands. The process turned out to be highly conflicting as a consequence of different facts: the conflict emerged between two groups farmers, since the very beginning of the conflict, to obtain the management of the agricultural committee; the alliances that the two groups established with political stakeholders like the Mayor's Office, the farmers'guerrilla, and the state and national authorities, said alliances contributed to modify the balance of power; and the acts in which an prominent engineer in the town from the National Agricultural Commission was involved, which would produce an armed struggle between the 'ejidatarios' (land borrowers) of Catemaco and Maxacapan. The conflict between the two towns would have an unexpected resolution: the disaggregation of part of Catemaco's land.
\end{abstract}

Keywords: Catemaco, Los Tuxtlas, Maxacapan, land reform, trade union, peasants.

\section{Reforma agrária e violência camponesa em Catemaco, Veracruz (México), 1921-1958}

\begin{abstract}
Resumo
O objetivo do artigo é mostrar as gestões que os camponeses de Catemaco, Veracruz, uma das populações que conformavam o Canton de los Tuxtlas, fizeram diante das autoridades agrárias para tentar obter terras. O processo foi sumamente conflitante como conseqüencia de diversos fatos: o conflito gerado entre dois grupos de camponeses, desde o mesmo começo do processo, por obter a liderança do comitê agrário; as alianças que os dois grupos estabeleceram com atores políticos como a Municipalidade (Ayuntamiento), a guerrilha agrária e as autoridades estatais e nacionais, alianças que contribuíram a modificar o balanço do poder; e os atos nos que esteve envolvido um engenheiro da Comissão Nacional Agrária, destacado na população, mesmos que provocariam um enfrentamento armado entre os ejidatarios de Catemaco e de Maxacapan. A conflitante situação entre as duas populações teria uma resolução inesperada: a desagregação de uma proporção do território catemaquense.
\end{abstract}

Palavras-chave: Catemaco, Los Tuxtlas, Maxacapan, a reforma agrária, sindicais, camponeses. 


\section{Introducción}

Los estudios realizados sobre la región de Los Tuxtlas, Veracruz, conformada por las poblaciones de San Andrés Tuxtla, Santiago Tuxtla y Catemaco, ubicad en la zona central de la planicie costera del golfo de México (mapa 1), han puesto especial atención en los dos primeros lugares, mientras que Catemaco ha permanecido prácticamente en la penumbra. Esta situación se explica por el hecho de que San Andrés y Santiago se disputaron, desde finales del virreinato hasta las primeras cuatro décadas del siglo XIX, la primacía política de la región, confrontación que culminó con la victoria de San Andrés y la efímera separación de Santiago. A lo anterior se debe sumar que las principales actividades económicas y comerciales se desarrollaban en esas dos poblaciones, además de que los principales propietarios y comerciantes, sobre todo de San Andrés, contaban con importantes extensiones de tierra en Catemaco, tal como ocurrió con las familias Carrión, Artigas, Villa y Turrent ${ }^{1}$. Desde esta perspectiva, no debe extrañar que Catemaco se haya concebido como un apéndice de San Andrés y Santiago, población admirada por su lago ${ }^{2}$.

Este trabajo centra su atención en los conflictos generados en el interior de Catemaco como consecuencia del proceso de reforma agraria iniciado en 1921 y que culmina en 1958, de manera momentánea, cuando Juan Hernández tomó el control del Comisariado Ejidal (CE), que se mantuvo hasta la década de 1960. El proceso de dotación de las tierras de Catemaco tuvo lugar en los años del denominado "agrarismo radical", promovido por el gobernador Adalberto Tejeda, y constituye un ejemplo de la manera en que las redes del tejedismo arraigaron en el nivel local. Es preciso destacar que la posesión de las tierras dotadas suscitó el enfrentamiento entre dos grupos de campesinos, quienes establecieron una serie de alianzas con actores políticos como el Ayuntamiento, la guerrilla agraria y las autoridades estatales y nacionales, alianzas que contribuyeron a modificar el balance de poder entre dos instancias que buscaban controlar el ejido y que mostraban la complicada dinámica existente en la población.

\footnotetext{
${ }^{1}$ SOUThWORTH, J. R., Veracruz Ilustrado, México, Editora de Gobierno del Estado de Veracruz, 2005, p. 148. Por ejemplo, Octaviano Carrión, según Southworth, poseía 950 hectáreas de tabaco, 200 en Catemaco y 750 en tres congregaciones de San Andrés Tuxtla (Comoapan, Bezoapan y Calería), mismas que colindaban con la primera población.

${ }^{2}$ GONZÁLEZ, José, Los Tuxtlas, México, Archivo General del Estado de Veracruz, 1991; MEDEL, León, Historia de San Andrés Tuxtla, 1525-1912, tomo I, México, Gobierno del Estado de Veracruz, 1993; REMY, H, "Tierra Caliente. Impresiones en México" en Cien viajeros en Veracruz. Crónicas y relatos, 1856-1874, tomo VI, México, Gobierno del Estado de Veracruz, 1992, p. 58. Un ejemplo de lo antes mencionado es el libro de León Medel que si bien tiene la intención de hacer una historia de San Andrés Tuxtla, incluye muchos documentos sobre Santiago, pero casi ninguno sobre Catemaco, situación similar a la de José González cuyo texto centra su atención en San Andrés y Santiago, en tanto que las únicas alusiones a Catemaco son aquellas referidas a su lago. De acuerdo con el viajero francés Remy, las tres poblaciones se manifestaban mutua hostilidad, de manera que "Santiago, cabecera del Departamento, siente profundo desprecio por San Andrés, San Andrés insulta a Tuxtla y a los catemacos. Catemaco, indiferente, hace valer su poderosa virgen". Las prácticas mágico-religiosas que se desarrollan en Catemaco han sido objeto de estudio por parte de los antropólogos, tal como se muestra en OLAVARRIETA, Marcela, Magia en los Tuxtlas, Veracruz, México, Instituto Nacional Indigenista, CONACULTA, 1990; VARGAS, Guadalupe, "Prácticas religiosas y New Age en Los Tuxtlas, Veracruz" en Contrapunto, No. 12, volumen 4, México, Editora de Gobierno del Estado de Veracruz, septiembre-diciembre de 2009.
} 
Aunque parezca paradójico, los principales beneficiarios del reparto agrario no serían los campesinos, sino los diversos dirigentes ejidales que disponían de la tierra según sus conveniencias.

\section{Mapa 1.}

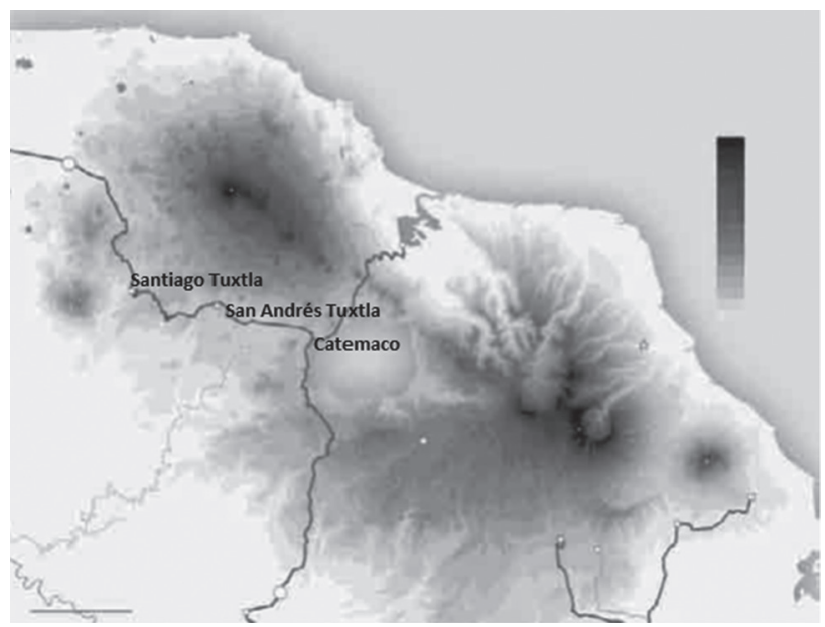

Fuente: Mapa tomado del Alfred Siemens, Una manera de ver Los Tuxtlas. Paisaje de Mesoamérica, México, CONABIO, 2009, p. 38.

El trabajo se divide en tres partes: en la primera se muestran los orígenes de la población hasta el momento del fraccionamiento de sus propiedades comunales a consecuencia de las políticas liberales. Conocer este proceso es de particular importancia porque, como lo menciona Emilio Kourí, se desconoce la forma en que de desposeyó de sus propiedades a los pueblos, además, se explica su reacción ante los cambios generados en el contexto rural posrevolucionario ${ }^{3}$.

En la segunda parte se analizan las gestiones realizadas por los campesinos catemaquenses para obtener tierras en dotación, lo cual permitirá entender los complejos procesos vividos por una población cuyos campesinos estaban divididos por cuestiones políticas. Si bien la reforma agraria buscó la equidad jurídica y social de los campesinos beneficiados ${ }^{4}$, no se puede pasar por alto las numerosas circunstancias políticas, sociales y económicas que modificaron el comportamiento de las poblaciones y provocaron profundas divisiones políticas generadas por la búsqueda del control del ejido.

\footnotetext{
${ }^{3}$ KOURÍ, Emilio, "Economía y comunidad en Papantla: reflexiones sobre la cuestión de la tierra en el siglo XIX”, en ESCOBAR, Antonio y ROJAS, Teresa (Coords.), Estructuras y formas agrarias en México. Del pasado al presente, México, CIESAS, Secretaria de la Reforma Agraria, CONACYT, Universidad de Quintana Roo, 2001, pp. 202-203.

${ }^{4}$ DEL REY POVEDA, Alberto y QUESNEL, André, "Las implicaciones intrafamiliares, intergeneracionales y migratorias de la política agraria en México. El caso del sur del estado de Veracruz, México", en Ulúa. Revista de Historia, Sociedad y Cultura, año 5, No. 9, México, Universidad Veracruzana, enero-junio de 2007, p. 59.
} 
En la tercera parte, se muestran las dificultades externas, pues se produjo un enfrentamiento con los campesinos de Maxacapan, ocasionado por la definición de los límites del ejido, que tuvo como resultado un violento enfrentamiento motivado por la intervención de un ingeniero de la brigada agraria, quien no buscó resolver el problema sino que trató de favorecer a los de la congregación. La conflictiva situación entre las dos poblaciones tuvo una resolución inesperada: la disgregación de una porción del territorio catemaquense para formar una nueva población que dependía de Maxacapan. La decisión de las autoridades agrarias contribuyó a agravar las tensiones entre los ejidatarios de Catemaco, mismas que cesarían cuando el CE de Juan Hernández tomó posesión, dado que este ejerció una política de represión en contra de sus detractores.

\section{El fraccionamiento de las tierras}

De acuerdo con Salvador Herrera, los primeros pobladores de Catemaco eran unos pescadores que se asentaron en "punta de pesquería". Al igual que San Andrés y Santiago, Catemaco perteneció durante la época colonial a los dominios del marquesado del Valle y dependía en lo administrativo y judicial de Santiago. ${ }^{5}$ Después de que se proclamó la independencia en 1821, San Andrés y Catemaco aprovecharon las nuevas circunstancias políticas para denunciar, el 11 de octubre de 1824 , que carecían de una propiedad territorial, condición que los tenía en un "estado de pobreza"6. A raíz de las medidas tomadas en contra de los españoles residentes en el país, entre las que se encontraba la orden de expulsión promulgada en 1829, el gobierno nacional determinó en 1833 que se declararían propiedades del Estado todas aquellas posesiones que hubieran tenido su origen en la conquista, situación en la que se encontraban las tierras del duque de Terranova y Monteleone, quien era el heredero del marquesado. Antes de que se tomara ese acuerdo, el Congreso había pedido, el 18 de mayo del mismo año, que las autoridades veracruzanas y las de los otros estados en los que había propiedades del Duque hicieran un recuento detallado de las mismas, se advertía que no debían permitir que este las vendiera o adjudicara a terceros. Como respuesta, Lucas Alamán, quien fungía como administrador de los bienes del duque desde 1825, envió una representación al Legislativo para que no se llevara a cabo la medida. Alamán logró su cometido, pues no solo evitó la expropiación de los bienes, sino que también retrasó la aplicación de la cláusula que evitaba su venta. El 30 de septiembre de 1837, el coronel Luis Ruiz, un rico comerciante de Alvarado, compró

\footnotetext{
${ }^{5}$ IGLESIAS, José María, Acayucan en 1831, México, Editorial Citlaltépetl, pp. 109, 113; GARCÍA, Bernardo, El Marquesado del Valle. Tres siglos de régimen señorial en Nueva España, México, El Colegio de México, 1969, pp. 57-60; HERRERA, Salvador, Entre la magia y la bruma. Estampas catemaqueñas, México, Instituto Veracruzano de Cultura, 2007, pp. 18, 24, 79; DE MEDINA, Juan, "Relación de Tlacotalpan y su partido" en ACUÑA, René (Ed.), Relaciones geográficas del siglo XVI: Tlaxcala, tomo II, México, UNAM, Instituto de Investigaciones Antropológicas, 1985, p. 290.

6 "Orden del 18 de junio de 1825" en BLÁZQUEZ, Carmen y CORZO, Ricardo (Coords.), Colección de Leyes y Decretos de Veracruz, 1824-1919. Tomo I. 1824-1927, México, Universidad Veracruzana, 1997, pp. 342-343. Las dos poblaciones también mostraron molestar por el hecho de que el Duque de Terranova les solicitó la entrega de sus fondos de comunidad en calidad de préstamo, lo cual, según decían, empeoró su "estado de pobreza".
} 
a Lucas Alamán una importante porción de las tierras pertenecientes al marquesado 7 . Unos años después, Ruiz vendería parte de esos terrenos a San Andrés Tuxtla, Santiago Tuxtla y Catemaco.

Catemaco compró sus tierras al coronel en 1839, pero se desconoce quiénes fueron los encargados de hacerlo, qué extensión compraron y cuánto pagaron, situación que contrasta con la de sus poblaciones vecinas de las que se tiene mayor información ${ }^{8}$. En 1850 se aumentó la extensión territorial de la población, merced a que el coronel hizo una donación de tierra, aunque tampoco se conocen sus dimensiones. En 1856 se realizó la última adquisición de tierra. Aunque se adujo que los vecinos compraron a Pedro García unos terrenos para aumentar su fundo legal, la transacción, en realidad, buscaba conservar las tierras pertenecientes a la cofradía de la virgen del Carmen, estratagema empleada también por los de Santiago que adquirieron las tierras de la cofradía de la virgen del Rosario y Comoapan que obtuvo las de la cofradía del Santísimo Sacramento ${ }^{9}$. Aunque no se tiene información respecto al monto de compra, no resultaría extraño pensar que la negociación realizada entre la cofradía y Catemaco haya tenido las mismas bases de otras transacciones mencionadas. En el caso de Santiago, por ejemplo, el mayordomo de la cofradía estipuló la venta las tierras para evitar que "personas ajenas" a la población las denunciaran y se quedaran con ellas, asunto explicable por el hecho de que las leyes de desamortización ordenaban su venta. Es preciso destacar que las tierras de la cofradía de la virgen del Carmen abarcaban desde la laguna hasta las inmediaciones de los cerros circundantes a la población, es decir, el pueblo de Catemaco prácticamente se asentaba en las tierras de la cofradía ${ }^{10}$. El proceso de compraventa generó disputas al interior de la comunidad, debido a que la virgen era la patrona del lugar, esto retrasó su aplicación por cuatro años. Finalmente, el gobernador determinó, el 15 de noviembre de 1860, que las propiedades territoriales pasaran a manos del Ayuntamiento para su administración y venta en pequeños lotes. También se dispuso que a los compradores indígenas se les dispensara del pago de

\footnotetext{
${ }^{7}$ Archivo Municipal de Jalapa, Actas de Cabildo de 1833, ff. 47, 115, 273-275, 290, 528-529 y Actas de Cabildo de 1834, f. 10; Nettie Lee Benson Latin American Collection, Fondo Lucas Alamán, documento 220, f.1 y documento 358, f. 10.

${ }^{8}$ Véase: JIMÉNEZ, Rogelio, "El proceso de reparto de la propiedad comunal en dos poblaciones del Cantón de los Tuxtlas, Veracruz durante la década de 1880" en Memoria y Sociedad, vol. 14, No. 29, Bogotá, Pontificia Universidad Javeriana, julio-diciembre de 2010, pp. 108-111.

9 JIMÉNEZ, Rogelio, “El proceso de...” Op. cit., p. 111; JIMÉNEZ, Rogelio, “Campesinos contra campesinos: conflictos agrarios y lucha por la tierra en Comoapan, Veracruz (1925-1942)" en Anuario de Historia Regional $y$ de las Fronteras, vol. 18, No. 2, Bucaramanga, Universidad Industrial de Santander, diciembre de 2013, p. 358; LÉONARD, Eric, “Avatares y descarrilamiento del proyecto agrario liberal. Disolución de la propiedad comunal y modernización agrícola en los Tuxtlas, 1880-1910", en Ulúa. Revista de Historia, Sociedad y Cultura, año 5, No. 9, México, Universidad Veracruzana, enero-junio de 2007, pp. 14.

${ }^{10}$ Acervo Histórico de Notarías del Distrito Federal, Notaría 426, vol, 2837, "Escritura de venta celebrada entre el coronel Luis Ruiz y Lucas Alamán”; IGLESIAS, José María, Op. Cit., p. 113; Solís, Ruth (Comp.), Veracruz en el Diccionario Universal de Historia y Geografia, 1853-1856, México, Gobierno del Estado de Veracruz, Secretaria de Educación y Cultura, 1998, p. 101; REMY, H., Op. Cit., p. 61. Iglesias no menciona la existencia de las tierras de la cofradía y solo refirió la presencia de una hacienda de ganado mayor, en la que se criaban 1400 reses. Esta información se repetiría en el Diccionario Universal. Remy refería que la cofradía era "muy rica" y era administrada por un sacerdote y una sociedad de "santas mujeres".
} 
la alcabala y del costo de la escritura de adjudicación ${ }^{11}$. Es probable que las tierras comunales hayan sido administradas por una Junta Agrícola, de la misma manera que se hacía en las otras poblaciones del Cantón y en algunas de sus congregaciones ${ }^{12}$. La política de fraccionamiento de la tierras comunales emprendida por el gobernador Juan de la Luz Enríquez (diciembre de 1884 a marzo de 1892) alcanzaría a Catemaco en julio de 1888, lo cual evidenciaba que fue la última población en realizar esta tarea, pues en San Andrés inició el proceso en 1885 y Santiago lo haría en $1887^{13}$. Para tal efecto, se constituyó una "Junta Divisionista de los Terrenos de Catemaco", integrada por Rafael Sarait (presidente), Ignacio González (secretario), B. Pereyra (tesorero), Tiburcio Sánchez y Juan Hernández (vocales). Todos eran miembros del Ayuntamiento, instancia encargada de la repartición de los terrenos debido a que la ley del 7 de marzo de 1874 estableció que estos organismos, en lugares de alta densidad indígena, debían realizar la "lotificación" en virtud de que las propiedades les pertenecían ${ }^{14}$. No existen mayores datos que permitan delinear el proceso de fraccionamiento, el cual concluyó el 14 de enero de 1890 con la división de la tierra en varias zonas, determinándose que los títulos de propiedad serían expedidos por la Junta y se ordenó la compra de diez hectáreas para el fundo legal, medida sustentada en el decreto del 4 de abril de 1856 que obligaba a destinar una parte de los terrenos ejidales para este fin $^{15}$.

El asunto del fraccionamiento de la tierra no generó problemas, algo similar a lo vivido en las otras poblaciones tuxtecas en donde no se manifestaron brotes de violencia o de descontento, circunstancias que, entre otros factores, se dieron gracias al control

\footnotetext{
11 “Circular del 16 de noviembre de 1860", en BLÁZQUEZ, Carmen y CORZO, Ricardo, Colección de leyes y Decretos de Veracruz, 1824-1919, tomo III, pp. 719-722, 737-742.

${ }^{12}$ Archivo General del Estado de Veracruz. Fondo Comisión Agraria Mixta, (en adelante AGEV. CAM) San Andrés Tuxtla, caja 25, exp. 25, ff. 116-120; AGEV. CAM, Catemaco, caja 101, exp. 152, f. 58; "Decreto 48 del 3 de julio de 1879", en BLÁZQUEZ, Carmen y CORZO, Ricardo, Colección de leyes y Decretos de Veracruz, 1824-1919, tomo VI, p. 581; "Decreto 25 del 25 de mayo de 1881", en BLÁZQUEZ, Carmen y CORZO, Ricardo, Colección de leyes y Decretos de Veracruz, 1824-1919, tomo VII, p. 241. La situación interna de Catemaco se tornó complicada en 1878, pues el Congreso decidió anular la elección del Ayuntamiento por no haber obtenido el número mínimo de votos, situación que provocó el encarcelamiento de los miembros de la Junta de Escrutinio. Es relevante mencionar que el 25 de mayo de 1881 se designó villa a Catemaco.

13 "Decreto 83 del 22 de diciembre de 1886", en BLÁZQUEZ, Carmen y CORZO, Ricardo, Colección de leyes y Decretos de Veracruz, 1824-1919, tomo VIII, p. 598; "Decreto 69 del 16 de diciembre de 1887", en BLÁZQUEZ, Carmen y CORZO, Ricardo, Colección de leyes y Decretos de Veracruz, 1824-1919, tomo IX, p. 241. Aunque el gobierno estatal insistía en la necesidad de acelerar el proceso de reparto de las tierras comunales, lo cierto es que desde 1886 el Congreso emitió una serie de decretos que lo postergaban.

${ }^{14}$ ESCOBAR, Antonio y GUTIÉRREZ, Ana María, "Dos momentos del proceso agrario veracruzano: el caso de Chicontepec" en Estudios campesinos en el Archivo General Agrario, volumen II, México, Registro Agrario Nacional, 1999, p. 215; VELASCO, José, El péndulo de la resistencia. (La defensa de la territorialidad y la autonomía indígena), México, Gobierno del Estado de Veracruz, 2002, p. 63. Desde 1856, Ignacio de la Llave concedió a los ayuntamientos la facultad de vender los excedentes de los terrenos de comunidad.

${ }^{15}$ AGEV. CAM, Catemaco, caja 101, exp. 152, ff. 12-13; "Decreto del 4 de abril de 1856", en BLÁZQUEZ, Carmen y CORZO, Ricardo, Colección de leyes y Decretos de Veracruz, 1824-1919, tomo III, p. 498; "Decreto 29 del 4 de julio de 1888", en BLÁZQUEZ, Carmen y CORZO, Ricardo, Colección de leyes..., Op. cit., tomo IX, p. 293.
} 
que los propietarios y las autoridades municipales ejercieron sobre la población, así como al hecho de que no existía un importante núcleo de población indígena, de tal manera que el poder político y económico era ejercido por una elite mestiza. Es de advertir que los campesinos fueron beneficiados con una acción de tierra, terrenos que después vendieron a diversos propietarios debido a que la mayoría no logró devengar el costo de las acciones. Sin embargo, resulta complicado determinar el número de beneficiarios y el tamaño de la acción, pues esta se determinaba en función de la superficie a fraccionar.

\section{El inicio de la gestión}

El 6 de marzo de 1921, el presidente municipal Salvador Viveros reunió a los vecinos de Catemaco para formar un Comité Particular Ejecutivo (CPE), acción que, según él, les permitiría reclamar las tierras perdidas a causa de la "inmoderada ambición" de los "terratenientes", quienes los obligaban a comprar la madera, los bejucos y el zacate requerido para sus labores cotidianas. El CPE se integró con Hilarión Bernal (presidente), Juan Barrios (secretario) y Reyes Aguilar (vocal). El acto contó con el aval del agente de propaganda agrícola Juan Rodríguez Clara, personaje de activa participación en la formación de los CPE de las otras poblaciones y congregaciones de la región de los Tuxtlas. Así, Catemaco inició sus gestiones en el marco de la primera etapa de gobierno de Adalberto Tejeda (1920-1924), caracterizada por la irrupción en la arena política de campesinos y trabajadores urbanos. El gobernador centró su atención en la reforma agraria y en la organización política del campesinado, motivo por el cual impulsó la formación de guerrillas campesinas para protegerse de las guardias blancas de los terratenientes; asimismo, promovió la organización rural en el ámbito local por medio de la presencia de dirigentes campesinos, a quienes encomendó la tarea de formar sindicatos campesinos y cooperativas en las distintas regiones de la geografía veracruzana. Tejeda logró poner en práctica sus medidas agraristas gracias al fortalecimiento de su base popular, a través de la formación de la liga de comunidades agrarias del estado de Veracruz (LCAEV) y de la promulgación de una legislación obrera de carácter radical. La lucha por el poder, tanto a nivel local como nacional, impidió que Tejeda, en su primera etapa de gobierno, lograra llevar a cabo la mayor parte de sus reformas, pero marcaría el rumbo a seguir en los años posteriores $^{16}$.

Tras la conformación del Comité, Viveros denunció, ante la Comisión Local Agraria (CLA), diversos atropellos por parte de los propietarios y le solicitó a Rodríguez Clara elaborar un informe, este fue realizado por Ángel Zamudio quien indicó que el pueblo

\footnotetext{
${ }^{16}$ FALCÓN, Romana y GARCÍA, Soledad, La semilla en el surco. Adalberto Tejeda y el radicalismo en Veracruz, 1883-1960, México, El Colegio de México, 1986, pp. 120, 127-128, 135, 143, 145, 163 165; FALCÓN, Romana, El agrarismo en Veracruz. La etapa radical (1928-1935), México, El Colegio de México, 1977, pp. 33, 35, 40, 43; BAITENMANN, Helga, "Rural Agency and State Formation in Postrevolutionary Mexico: The Agrarian Reform in Central Veracruz (1915-1992)", tesis doctoral, Anna Arbor, New School for Social Research, 1997, pp. 81, 105, 131; BLÁZQUEZ, Carmen, Breve historia de Veracruz, México, FCE, 2000, pp. 190-191. La Ley de participación de Utilidades y la Ley de enfermedades profesionales y no profesionales buscó ofrecer soluciones a las demandas laborales de los trabajadores, pero provocó fricciones entre Tejeda y los empresarios de Veracruz, Córdoba y Orizaba.
} 
no conservaba "ni un palmo de tierra" porque las habían vendido de manera gradual y solo había "potreritos" en los que se criaban reses, vacas y cerdos. Zamudio no exageraba en su apreciación. El censo agrario de 1922 mostraba que 32 propietarios arrendaban variadas extensiones de tierra a 223 campesinos. El 15 de abril de 1921, el CPE formalizó su petición de tierras ${ }^{17}$. Como no existen evidencias de dicha petición, resulta pertinente preguntarse cuál fue la razón por la que el CPE presentó la denuncia. La evidencia muestra que el CPE y el Ayuntamiento estaban enfrascados en un conflicto, ya que el segundo se negó a realizar el padrón general del pueblo pese a que lo solicitó el gobernador.

Debido a que el Ayuntamiento no entregó el censo en tres ocasiones, la CLA ordenó que lo realizara el ingeniero Jorge Vizcaíno. En su informe, el ingeniero indicó que el CPE estaba desmembrado por la salida de Hilarión Bernal y de Reyes Aguilar, en octubre de 1921. Como no se aceptó que la presidencia quedara en manos de Pedro Rosario, personaje a quien postuló Bernal, el secretario Juan Barrios asumió el control del órgano. El nuevo CPE, electo en marzo de 1922, estaba integrado por Pedro Rosario (presidente), Juan Barrios (secretario) y Miguel Forman (vocal). A pesar de que Vizcaíno entregó su informe, la CLA no lo consideró satisfactorio y pidió al ingeniero Álvaro Fernández que realizara uno que permitiera justificar la demanda de tierra. El proceso se detuvo hasta el 23 de octubre de 1926, día en el que Manuel Ramírez, Alberto Gómez y Alberto Marcial, en nombre de los agricultores de Catemaco, pidieron la resolución del expediente. A pesar de esto, la CLA informó que no existía evidencia del despojo y ordenó al ingeniero Rafael Robles levantar un nuevo censo, circunstancia aprovechada por los de Catemaco para pedir les entregaran unos terrenos ubicados en la congregación de Calería, pretensión rechazada por la CLA bajo el argumento de que las tierras se otorgaron a la población en 1926. Sin embargo, el ingeniero justificó el proceder de los catemaquenses, pues mencionaba que esos terrenos los utilizaban para sembrar maíz y frijol. A fin de aumentar la presión en contra de las autoridades agrarias, Manuel Ramírez, Alberto Gómez y Alberto Marcial, ahora como miembros del Sindicato de Obreros y Campesinos de Catemaco, solicitaron una pronta respuesta en virtud de que, según ellos, los de Calería invadían sus terrenos y les cobraban altos arrendamientos ${ }^{18}$.

El 8 de marzo de 1927, Robles informó que en Catemaco había 604 jefes de familia necesitados de tierra. Para realizar la dotación se podían afectar las propiedades de Manuel Turrent, Octaviano Carrión y Alberto Alegría, aunque existía el problema de que las de Carrión se entregarían a la congregación de Maxacapan y que Alegría había dividió las suyas para venderlas a los vecinos de Catemaco ${ }^{19}$. Sin tomar en cuenta el

\footnotetext{
${ }^{17}$ AGEV. CAM, Catemaco, caja 101, exp. 152, ff. 1-4, 11, 14-15, 17-27.

${ }^{18}$ AGEV. CAM, Catemaco, caja 101, exp. 152, ff. 17-20, 30-31, 33-47, 49, 53, 52, 55, 59, 67-106, 109, 111-112, 116, 119, 127-147, 295-296.

${ }^{19}$ AGEV. CAM, Catemaco, caja 101, exp. 152, ff. 298-299, 301-304, 306, 308-310, 314; VELASCO, José y SANTOS, Lucía, "La reforma agraria en el municipio de Cosamaloapan, Veracruz (México), 1915-1945" en Anuario de Historia Regional y de las Fronteras, vol. 19, No. 2, Bucaramanga, Universidad Industrial de Santander, 2014, p. 474. La impugnación del censo agrario se convirtió en un medio eficaz para que los propietarios retrasaran los procesos agrarios, situación que no solo se observó en Catemaco sino también
} 
informe del ingeniero, el Sindicato de Obreros y Campesinos volvió a pedir, en 1928, la devolución de las tierras entregadas a Calería, a la vez que solicitó la resolución de los expedientes de Dos Amates, La Candelaria y Cartagena. Con esta acción, el Sindicato asumía el papel de portavoz de los grupos campesinos de la región. Estas peticiones serían respaldadas por Rafael Pérez Vidal, presidente municipal de Catemaco, ello evidenciaba una alianza entre el CPA y el Ayuntamiento, alianza que el tejedismo consideraba fundamental para la consolidación del proyecto agrarista, puesto que el control de la administración municipal implicaba adentrase en las profundidades del sistema político estatal y, a la vez, afianzar sus alianzas con políticos, líderes y caciques. Su segunda etapa de gobierno, considerada como la "época dorada del agrarismo", se caracterizó, entre otras cosas, por la movilización política de las organizaciones obreras y campesinas, lo cual provocó, en palabras de Romana Falcón, una verdadera "revolución política", pues las organizaciones se convirtieron en elementos de apoyo al gobierno y sus líderes ocuparon cargos políticos.

Tejeda también ejerció un control sobre la burocracia, el poder judicial y la CLA, además logró la consolidación de las guerrillas agrarias. Con estas acciones, Tejeda construyó una estructura política adecuada para implementar las reformas radicales. La política agrarista de Tejeda modificó de manera significativa la estructura de la propiedad rural en Veracruz, de manera que, entre 1928 y 1932, se realizaron 1109 peticiones de dotación de tierra, de las cuales se resolvieron provisionalmente $493^{20}$.

Con la intención de agilizar el proceso, la CLA ordenó al ingeniero Segundo Maldonado trasladarse a Catemaco. Tras su arribo, en agosto de 1928, el ingeniero sustituyó al CPA, acto que motivó la separación de un grupo de campesinos. El nuevo Comité estaba integrado por Juan Barrios (presidente), Leonardo Santos (secretario) e Ignacio Zacarías (tesorero). Maldonado notificó a la CLA que había 960 jefes de familia pero solo 592 tenían derecho, cifras que contrastaban con las proporcionadas por Robles en su anterior informe ${ }^{21}$. Resulta complicado explicar las variaciones en las cifras. No se puede aducir que Maldonado aumentó el número de habitantes para beneficiar a una mayor cantidad de ellos, ya que se debe tener en cuenta que disminuyó el número de los posibles agraciados (592 por 604). Aunque el ingeniero no mencionó el número de hectáreas

\footnotetext{
en Cosamaloapan y otras poblaciones veracruzanas.

${ }^{20}$ GINZBERG, Eitan, "Formación de la infraestructura política para una reforma agraria radical: Adalberto Tejeda y la cuestión municipal en Veracruz, 1928-1932”, en GARCÍA, Bernardo y SKERITT, David (Eds.), La Revolución Mexicana en Veracruz. Antología, México, Gobierno del Estado de Veracruz, 2009, pp. 381383, 390-392, 401, 437, 439; FALCÓN, Romana, Op. Cit. pp. 47-48, 63, 65; FALCÓN, Romana y GARCÍA, Soledad, La semilla en el surco ..., pp. 123, 125, 179, 194, 198, 223-224; LÉONARD, Eric y VELÁZQUEZ, Emilia, "El reparto agrario y el fraccionamiento de los territorios comunitarios en el sotavento veracruzano: construcción local del Estado e impugnación del proyecto comunal", en VELÁZQUEZ, Emilia, et al., El Istmo mexicano: una región inasequible. Estado, poderes locales y dinámicas espaciales (siglos XVIXXI), México, CIESAS, 2009, p. 404; BLÁZQUEZ, Carmen y CORZO, Ricardo, Colección de leyes y Decretos de Veracruz, 1824-1919. p. 191. Ginzberg explica que el radicalismo de Tejeda se daba por dos razones: el reducido tiempo político del que disponía para darle forma a un nuevo orden social que resultara irreversible y el intento de las autoridades centrales de desligarse de sus obligaciones sociales. Para llevar a cabo su labor, Tejeda pensaba que se debía desligar de los medios jurídicos y administrativos que la Constitución y la legislación ponían en manos del Estado.

${ }^{21}$ AGEV. CAM, Catemaco, caja 101, exp. 152, ff. 317-319, 320-324, 326, 330, 332-333, 336-339, 356.
} 
a otorgar, sí refirió la afectación de los predios: Olotepec, de Alberto Turrent; Plan de Chilapa, de María Cinta; y Matacapan, de Matilde Rosa Carrión (ver mapas 2 y 3).

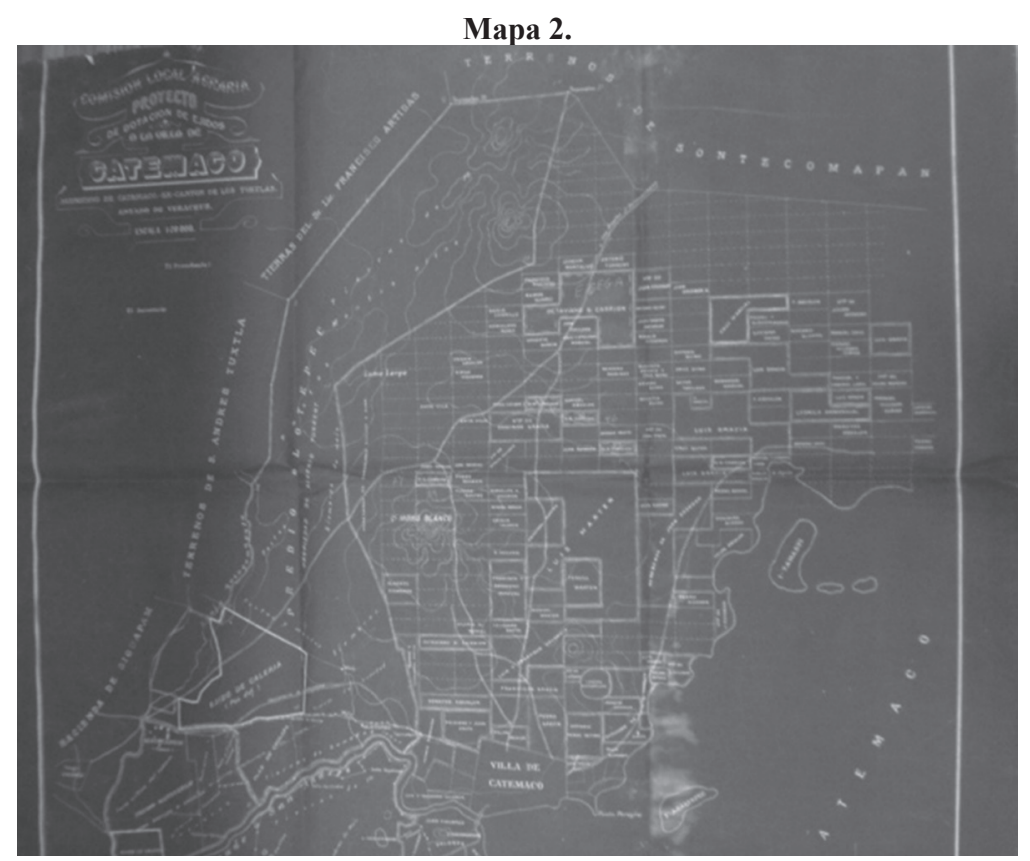

Fuente: AGEV. CAM, Planoteca, caja 39, "Proyecto de dotación de ejidos a la villa".

Como el CPE consideraba que había elementos para emitir un dictamen, acusó a la CLA de retrasarlo, lo cierto es que el organismo encontró irregularidades en el registro de una de las propiedades afectables (Plan de Chilapa no estaba inscrito en el Registro Público de la Propiedad). La tensión existente entre los campesinos provocó que Barrios, líder del CPE, fuera substituido el 11 de mayo de 1929, esto hizo que Barrios se uniera al "movimiento infidente" del general Pablo Escobar ${ }^{22}$. El argumento esgrimido por Santos no era convincente en virtud de que la rebelión escobarista había sido aniquilada a finales de marzo de ese año ${ }^{23}$. El CPE dirigido por Santos tendría que lidiar con la animadversión de Gabriel Cárdenas, presidente de la Junta de Administración Civil (JAC).

\footnotetext{
${ }^{22}$ AGEV. CAM, Catemaco, caja 101, exp. 152, ff. 357-360, 362, 364-365, 368-372, 375, 378, 381-383.

${ }^{23}$ MEYER, Lorenzo, Historia de la Revolución Mexicana. 1928-1934. El conflicto social y los gobiernos del Maximato, tomo 13, México, El Colegio de México, 2000, p. 269; MEYER, Lorenzo, SEGOVIA, Rafael y LAJOUS, Alejandra, Historia de la Revolución Mexicana. 1928-1934. Los inicios de la institucionalización, tomo 12, México, El Colegio de México, 1981, pp. 65, 67-80; DULLES, John, Ayer en México. Una crónica de la Revolución (1919-1936), México, FCE, 1989, pp. 402-414. La rebelión escobarista tuvo sus orígenes en el intento de Calles de resolver el problema de la sucesión presidencial, motivo por el cual eliminó de la carrera a los generales obregonistas. La rebelión inició el 3 de marzo de 1929 cuando dos contingentes acantonados en Veracruz se rebelaron al mando del general Aguirre, al mismo tiempo que se proclamaba el Plan de Hermosillo que impugnaba la "imposición” de Aarón Sáenz como candidato presidencial. Los rebeldes fueron derrotados en ciudad Jiménez, Chihuahua, el 30 de marzo del mismo año. La rebelión le ofreció a Calles la oportunidad de librarse de los generales de cuya lealtad dudaba, así como de los obregonistas civiles que lo combatían.
} 
Mapa 3.

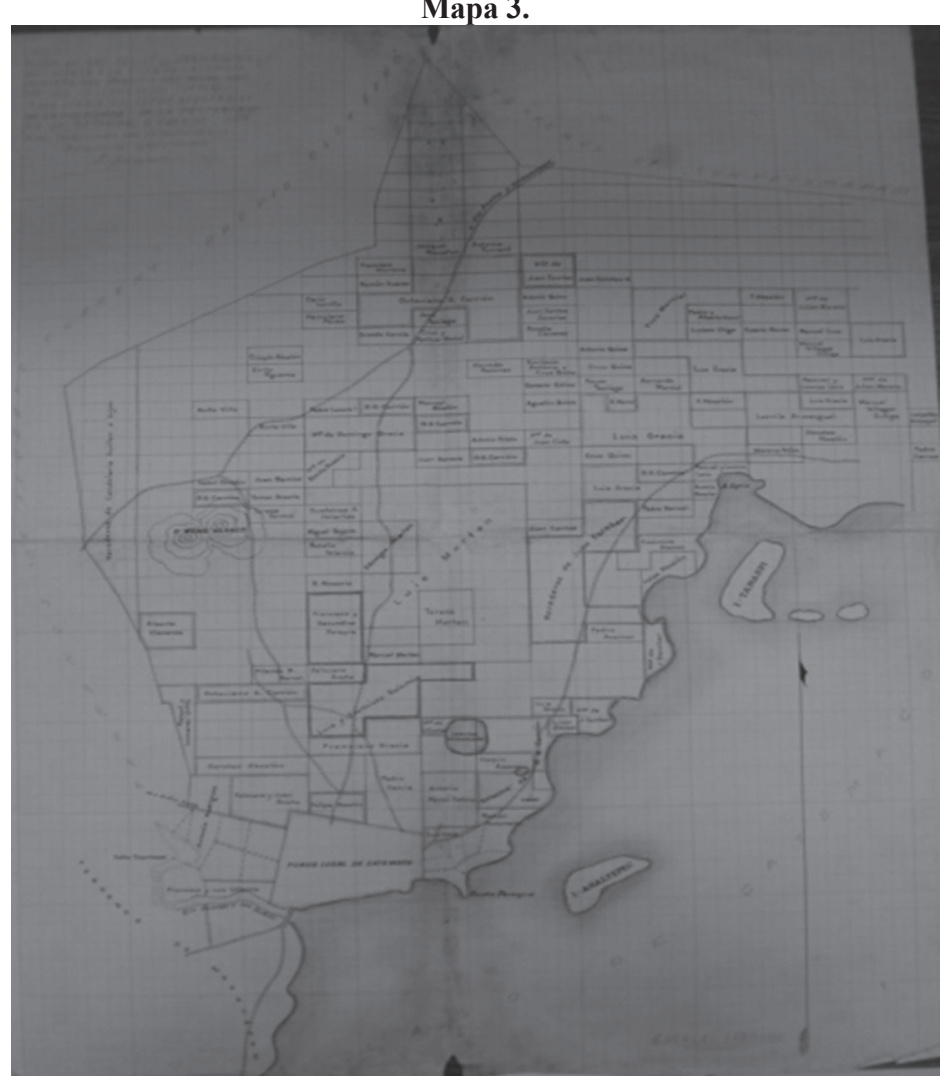

Fuente: AGEV. CAM, Planoteca, caja 39, "Pequeñas propiedades que afectan a la villa y que señala los lotes afectables de la propiedad de la testamentaría de Octaviano Carrión”.

Por tal motivo, la CLA le pidió a la JAC no obstruir las labores del CPE, pues los asuntos agrarios eran independientes de los administrativos. La recomendación no surtió efecto y los problemas entre los dos órganos continuaron. El enfrentamiento entre estas dos esferas de poder fue recurrente, tanto en este poblado como en otros lugares del estado de Veracruz, debido a que el CPE se constituyó en una estructura de gobierno local paralela a la municipal, esta situación suscitó problemas en la delimitación del espacio de acción de cada uno de los organismos ${ }^{24}$. Finalmente, la CLA determinó, el 27 de diciembre de 1929, dotar a Catemaco de 2530 hectáreas, provenientes de los predios Olotepec y Plan de Chilapa, de Alberto Turrent (184180 has.); Chalchoapan, de la testamentaria de Octaviano G. Carrión (506-20 has.); y Matacapan, de Matilde Rosa Carrión (182 has. $)^{25}$.

\footnotetext{
${ }^{24}$ BAINTENMANN, Helga, "Reforma agraria y ciudadanía en el México del siglo XX", en GÓMEZ, Francisco Javier, Paisajes mexicanos de la reforma agraria, México, El Colegio de Michoacán, 2007, pp. 78, 81; BAINTENMANN, Helga, "Rural Agency and State Formation in Postrevolutionary Mexico: The Agrarian Reform in Central Veracruz (1915-1992)", tesis doctoral, Ann Arbor, New School for Social Research, 1997, p. 412.

${ }^{25}$ AGEV. CAM, Catemaco, caja 101, exp. 152, ff. 387-408, 412-414.
} 


\section{División política de la comunidad y problemas de límites}

La resolución solo agudizó los conflictos internos, pues la CLA recibió un comunicado de Encarnación Domínguez, que notificaba la reinstalación del Comité Agrario "Miguel Hidalgo". La noticia era relevante por dos situaciones: Juan Barrios volvía a la escena agraria y se establecía un comité paralelo apoyado por la autoridad municipal. La CLA le advirtió a Domínguez que las leyes agrarias no permitían el funcionamiento de dos comités, en consecuencia, solo reconocería el de Santos. Encarnación hizo caso omiso de la advertencia y buscó asumir las actividades que correspondían al CPE. La pugna entre los dos grupos tuvo una resolución inesperada. El 21 de abril de 1930, Rafael Pérez Vidal, quien fungía como representante del CPE, denunció al presidente de la JAC, con el apoyo de la guerrilla municipal, arrestó al CPE, encabezado por Santos, así como a varios campesinos, que de acuerdo a lo declarado trabajaban de manera "ilegal" en el predio Olotepec. Pérez alegaba que la acción de Gabriel Cárdenas constituía una violación a sus garantías individuales, pues no tenía la facultad para interferir en las decisiones agrarias. Tres días después, la CLA recibió una carta firmada por un grupo de vecinos en la que se informaba que el grupo de Domínguez sembraba los terrenos de Olotepec, los mismos que, según Cárdenas, no se podían ocupar. El presidente de la JAC, por su parte, también remitió una carta al gobernador quejándose de las acciones del CPE, pero la CLA le aclaró que el Ayuntamiento mantenía una marcada hostilidad en contra del CPE, razón por la cual sostenía un "comité ficticio", a pesar de la ilegalidad del hecho ${ }^{26}$.

Cárdenas no tomó en cuenta las advertencias, puesto que buscaba menoscabar la labor agraria del Comité elegido por los campesinos. Por esta circunstancia, la CLA le ordenó a Cárdenas resguardar los terrenos para evitar que Domínguez los tomara en posesión. No obstante, por paradójico que parezca, Cárdenas trató de imponer a Domínguez como presidente del CPE. Para acabar con la problemática, el gobernador pidió al ingeniero Luis Canseco hacer la entrega del ejido previniendo dos problemas. El primero concernía a la petición de Luis Carrión, hijo de Matilde Rosa Carrión, para que no afectara Matacapan, ya que decía tener solo 249 hectáreas, de las cuales se utilizaban 90 para sembradíos y el resto estaba ocupado por pastos "artificiales" (40 has.), caña de azúcar (10 has.), árboles frutales (10 has.), pastos naturales y monte bajo $(99 \text { has. })^{27}$. De acuerdo con lo anterior, no se podía afectar una propiedad carente de la extensión mínima requerida por las leyes agrarias, además, su negociación tabacalera necesitaba de las tierras para subsistir, en virtud de que el cultivo de la hoja exigía el descanso periódico del terreno por su composición arenosa ${ }^{28}$. Carrión advertía que con la afectación, sus tierras se volverían improductivas, generando fatales consecuencias para la región. El segundo problema se refería al enfrentamiento entre Catemaco y

\footnotetext{
${ }^{26}$ AGEV. CAM, Catemaco, caja 101, exp. 152, ff. 415, 418-419, 420-422, 427-428.

${ }^{27}$ AGEV. CAM, Catemaco, caja 101, exp. 152, ff. 423-426, 429-432.

${ }^{28}$ GÓMEZ, Laura Guillermina, "Legislación e instituciones agrarias en México, 1911-1924” en Anuario Colombiano de Historia Social y de la Cultura, vol. 40, No. 1, Bogotá, Universidad Nacional de Colombia, enero-junio de 2013, pp. 287-288. Los argumentos de Carrión evidenciaban su amplio conocimiento de las estipulaciones agrarias incluidas en el reglamento del 10 de abril de 1922, en la cual se exceptuaba del reparto agrario a las negociaciones agrícolas que contaran con plantaciones.
} 
Maxacapan por la posesión de los terrenos de Octaviano Carrión. A fin de allanar los inconvenientes, se recomendó a Canseco que el ejido de Catemaco incluyera los terrenos ocupados por los de Maxacapan, resolución que agravó la problemática ${ }^{29}$.

Ante este hecho, el ingeniero convocó a una reunión a los representantes de Maxacapan y de Catemaco con el objeto de llegar a un acuerdo sobre los terrenos denominados Chalchoapan y Zanja Honda. A la reunión asistieron Leonardo Santos y Gregorio Bustamante, presidente y secretario del CPE de Catemaco, Cirilo Santos y Manuel Campo, presidente y secretario del CPE de Maxacapan, Gabriel Cárdenas y Santiago Gracia, presidente y secretario de la JAC de Catemaco, Andrés Abajan, agente municipal de Maxacapan y algunos vecinos de los dos poblados. Los de Maxacapan alegaron que desde 1924 ocupaban las tierras y por razones que desconocían, no se incluyeron en su dotación, por lo cual solicitaban un cambio de localización, aunque advertían que las ocuparían mientras no se emitiera una resolución. Canseco propuso varias soluciones rechazadas por ambas representaciones. Sin embargo, los de Catemaco sugirieron investigar si Carrión poseía otros terrenos afectables en un radio menor a siete kilómetros y en caso de tenerlas, podían utilizarlas mientras se resolvía el conflicto. Es de advertir que la afirmación de los de Catemaco no tenía ningún matiz demagógico, tal como lo demostraron los sucesos posteriores, cuando se les puso en posesión provisional de 2128 hectáreas, el 15 de junio de 1930, el ingeniero les advirtió que no entregaba la totalidad de las tierras, debido a que el predio Chalchoapan estaba ocupado por los campesinos de Maxacapan ${ }^{30}$.

La promesa de la dotación volvió a intensificar el conflicto entre el Comité Particular Administrativo Agrario (CPAA) y el presidente de la JAC. El primero denunció que desde 1926 habían sido hostilizados por un grupo de "campesinos", conformado por peones acasillados, pequeños propietarios, servidores públicos y "servidores de los terratenientes", que no tenían derechos agrarios pero habían ocupado una parte de las tierras porque contaban con el apoyo del Ayuntamiento. El CPAA manifestó no haberles negado el derecho a cultivar, solo les solicitó su organización, propuesta negada por los "invasores", también se negaron a pagar los gastos correspondientes al uso del ejido. No tomaron en cuenta las recomendaciones de la Liga de Comunidades Agrarias (LCA) y del ingeniero Canseco de unirse al proyecto ejidal encabezado por ellos. Por el contrario, los "invasores" trataron de desorganizar a sus compañeros. A causa de los anteriores motivos, el CPAA solicitó la exclusión a 18 vecinos del padrón agrario, con ello se pondría fín a los problemas, aunque advertía no pedir informes a la autoridad municipal sobre esas personas, pues estaban seguros de ser de la misma "estirpe reaccionaria"31.

\footnotetext{
${ }^{29}$ AGEV. CAM, Catemaco, caja 101, exp. 152, ff. 434-435, 474; AGEV. CAM, Maxacapan, exp. 188, ff. 3031, 123. Los problemas entre las dos poblaciones comenzaron en abril de 1926. De acuerdo con Primitivo Valencia, los campesinos de Catemaco apoyaron la invasión de los terrenos, promovida por Manuel Turrent y Octaviano Carrión. A Maxacapan se le otorgaron 750 hectáreas en diciembre de 1926, pero unos meses después, en específico el 18 de abril de 1927, la CLA determinó que solo se le entregarían 500.

${ }^{30}$ AGEV. CAM, Catemaco, caja 101, exp. 152, ff. 436-437, 440-442, 448-456, 459, 461-463, 466-471, 473, 475-480.

${ }^{31}$ AGEV. CAM, Catemaco, caja 101, exp. 152, ff. 482, 485-486, 490-493, 495-497, 499-503.
} 
En la lista aparecía en primer lugar el nombre del presidente del Comité que la CLA no reconoció (Encarnación Domínguez), el de sus hermanos (Felipe y Erasmo Domínguez) y algunos individuos del ayuntamiento (Manuel Santos Bustamante y Santiago Gracia Mantilla). Es evidente que el CPAA pretendía expulsar a sus principales antagonistas.

En octubre de 1931, el CPAA, ahora encabezado por Juan Reyes, volvió a retomar el asunto de Chalchoapan, argumentaba requerir esas tierras por haber aumentado el número de sus afiliados, además tenía conocimiento que los de Maxacapan no las cultivaban sino las arrendaban a particulares. También aseveraba que los terrenos ayudarían a mejorar las condiciones de su ejido, pues podrían ampliar la extensión de sus cultivos y dejarían de utilizar los ubicados entre "cascajales" y cerros.

La CLA no se comprometió a realizar la entrega, por tal motivo el CPAA remitió una carta al gobernador, el 22 de noviembre de ese año, en ella manifestaba su rechazo a la reforma del artículo 10 de la ley del 6 de enero de 1915, dado que consideraba "descabellado" desconocer la personalidad jurídica de los pueblos, lo que desde su interpretación contribuiría a despojarlos de la posesión definitiva de su ejido. En segundo lugar, expresaban querer el predio Zanja Honda como parte de la dotación definitiva, en manos de los de Maxacapan, quienes por razones "políticas" lo arrendaban a los terratenientes. Como se puede apreciar, la autoridad agraria de Catemaco buscaba apropiarse de unos terrenos que no estaban en disputa y que ni siquiera habían sido considerados como parte de la dotación original ${ }^{32}$.

La situación no se volvió más conflictiva, debido a que el CPAA se enfrentó con un problema imprevisto generado por la llegada de un grupo de colonos provenientes del centro del país, quienes en un principio intentaron ocupar unos terrenos en Sontecomapan y después buscaron ocupar unas tierras de Catemaco. El CPAA acusaba a los "enemigos de la causa agraria" de haber azuzado a los colonos para "saciar sus deseos insanos". De acuerdo con la autoridad agraria, los principales instigadores del movimiento eran Donato Castillo, quien se ostentaba como presidente de un Comité Agrario carente de reconocimiento oficial, Flavio Palacios, exjefe de los colonos, Santiago Gracia, secretario del ayuntamiento, Gabriel Cárdenas, expresidente del ayuntamiento, Encarnación Domínguez, P. García y otros más. Como ellos eran comerciantes y propietarios de tierras, desconocían los ideales del agrarismo y solo buscaban trastocar a la organización campesina para poner en práctica sus "torcidos ideales". Ante este panorama, el CPAA pidió a la LCA no autorizar la petición de los denominados "colonos de Sontecomapan", pues provocaría perjuicios a los ejidatarios. Su acusación se fundamentaba en las anteriores rencillas que habían tenido con Cárdenas y Domínguez. La petición del CPAA encontró apoyo de la LCA, organismo que rechazó la solicitud de los colonos ${ }^{33}$.

\footnotetext{
${ }^{32}$ AGEV. CAM, Catemaco, caja 101, exp. 152, f. 507-508, 515.

${ }^{33}$ AGEV. CAM, Catemaco, caja 101, exp. 152, ff.13-514, 518-519, 523-525, 527-528. Las autoridades agrarias le informaron al ingeniero que el fundo legal debía tener una superficie cuadrada cuyos lados variarían entre 500 y 1500 metros y se debía localizar en el centro del pueblo. Se debía trazar el perímetro en un lugar que tuviera el menor número de accidentes topográficos. Las avenidas debían correr de oriente a
} 
Una vez resuelto el problema de los colonos, el CPAA volvió a insistir en reiteradas ocasiones que se les entregaran las tierras faltantes, pero se encontraron con la oposición de los de Maxacapan. La presión política contra el CPAA volvió a manifestarse en noviembre de 1932 cuando Carlos Pascal, encargado de la organización agraria, solicitó su destitución ante la CLA, pero el Comité se defendió con el argumento de que los ejidatarios no habían presentado ninguna queja en su contra, por el contrario, gozaban de aceptación porque respetaban los acuerdos suscritos en las asambleas. Pidieron que la renovación del CPAA se aplazara hasta tener la posesión definitiva e instaron a que se les informara quiénes habían sido los promotores de una maniobra que afectaba sus intereses.

La CLA no modificó su decisión y ordenó, el 11 de noviembre de 1932, que el ingeniero Miguel Uribe realizara el reemplazo. Antes de dejar el cargo, Juan Reyes recordó al subdelegado José Ángel Sarmiento que faltaba entregar 402 hectáreas, mismas que se podrían tomar de los predios Cacahuatena y El Pozo, de Manuel Turrent. Esta petición carecía de fundamento pues no estaba contemplada en la delimitación original, pero daba cuenta de las tentativas de una autoridad ejidal que buscaba ampliar el ejido a costa de sus colindantes. La nueva directiva del CPAA estuvo encabezada por Leonardo Santos, quien prosiguió las gestiones de Reyes sin obtener éxito, hecho que fue tomado como excusa por algunos ejidatarios para solicitar la remoción de $\operatorname{Santos}^{34}$.

El movimiento opositor era dirigido por Juan Reyes. Con la intención de mediar en el asunto, el delegado Silverio Pablo Hernández informó a la CLA la inexistencia de razones para sustentar la remoción del presidente y sugirió más bien destituir al secretario suplente, cuyo puesto debía ser ocupado por Maximiliano Zacarías. Como respuesta, la CLA le pidió abstenerse de participar en el conflicto, ya que solo las autoridades nacionales tenían la potestad de remover a los miembros de un Comité.

En noviembre de 1933, la CLA tomó la decisión de separar a Santos y nombrar en su lugar a Crescencio Escobar, acción que no logró acabar con las disputas internas, pues el 30 de mayo de 1935 un grupo de campesinos remitió una carta a la CLA, acusando a Escobar de haber ordenado el despojo de sus parcelas. Por tal motivo, Francisco Velázquez, delegado del Departamento Agrario (DA), en agosto de ese año ordenó realizar una investigación y en caso de comprobarse las imputaciones extender un extrañamiento al Comisariado Ejidal (CE). Por su parte, el CE denunció que Bruno Vázquez, Leonardo Santos y Marciano Villegas fueron los responsables del despojo de las parcelas. Como se puede advertir, el CE buscó implicar al anterior presidente del CPAA en un acto que a todas luces era arbitrario. Aunque no se comprobó la acusación, esta denotaba el tipo de ambiente político vivido al interior del ejido y la existencia de dos agrupaciones opuestas ${ }^{35}$.

poniente y de norte a sur. Las calles debían medir 15 metros, de los que se descontarían 2,40 para banquetas. Las manzanas se trazarían de manera rectangular o cuadrada con una superficie de una hectárea. En el trazo se debían considerar espacios para la escuela, los edificios públicos y jardines.

${ }^{34}$ AGEV. CAM, Catemaco, caja 101, exp. 152, ff. 531-532, 534-535, 537-538, 540-541, 543-544, 546-547, 550-551, 553-554, 560, 562, 564, 566, 568-569, 573-574.

${ }^{35}$ AGEV. CAM, Catemaco, caja 101, exp. 152, ff. 577-578, 585, 587-588, 590. 
El conflicto se agudizó en diciembre de 1935 cuando el grupo de Santos ocupó la Casa de Sesiones, esto generó la molestia del Comité Municipal del Partido Nacional Revolucionario (PNR) de Catemaco, quien pidió a la Comisión Agraria Mixta (CAM) investigar los hechos. La petición del Comité Municipal era explicable por el hecho de que el CE tenía estrechos vínculos con el PNR, lo cual significaba la pérdida de poder del tejedismo en la región. Es de interés recordar que tras la fundación del PNR (en 1929), y en consonancia con lo que pasaba en el ámbito nacional, la LCAEV se dividió en tres grupos: la Liga Comunista, la Liga Blanca y la Liga Roja. La primera era controlada por el Partido Comunista, la segunda por el PNR y la tercera por Tejeda. El PNR sería utilizado como un medio para adentrarse en los intersticios del poder local y con ello crear una maquinaria política paralela e independiente del tejedismo, cuya intención sería arrebatar el control sobre el aparato político administrativo y de esa manera desmantelar la red de alianzas y pactos que le daba poder informal sobre algunos distritos rurales ${ }^{36}$. A diferencia de Santiago Tuxtla en donde la influencia del tejedismo seguía vigente, en Catemaco no solo se difuminó sino que la organización agraria se integró al proyecto nacional encabezado por el PNR. La oposición contra el CE volvió a manifestarse en el transcurso de 1937, tanto la CAM como la jefatura de la zona ejidal recibieron varias cartas en las que se denunciaban sus arbitrariedades. Un ejemplo es el de Adela Figueroa que fue despojada de su parcela y aunque la Asamblea general reconoció sus derechos, lo cierto es que la amenazaron con volver a quitársela. Ella solicitó el auxilio de Francisco Velasco, presidente suplente del CE, pero este alegó que no podía hacer nada para arreglar el asunto.

Para fortalecer su posición, el CE ofreció, junto con otras agrupaciones agrarias de la región, apoyo al PNR en las próximas elecciones estatales. La tensión existente entre ejidatarios y CE alcanzó su punto máximo en los primeros días de diciembre de 1937, dado que el presidente y el tesorero de la organización presentaron su renuncia ante la Asamblea general. El ingeniero Agustín Moreno mencionaba, en su informe a

\footnotetext{
${ }^{36}$ GINZBERG, Eitan, "Formación de la infraestructura política...", Op. cit., pp. 382-383; FALCÓN, Romana, pp. 60, 62, 112, 121-125; FALCÓN, Romana y GARCÍA, Soledad, Op. Cit., pp. 311, 331; MALDONADO, Serafín, De Tejeda a Cárdenas. El movimiento agrarista de la Revolución Mexicana, 1920-1934, México, Editorial Universidad de Guadalajara, 1992, pp. 47, 54, 61-63, 78, 112; BLÁZQUEZ, Carmen, Colección de leyes..., Op. cit., p. 191; LÉONARD, Eric y VELÁZQUEZ, Emilia, "El reparto agrario..." p. 400; OTERO, Gerardo, ¿Adiós al campesinado? Democracia y formación politica de las clases en el México rural, México, Universidad Autónoma de Zacatecas, 2004, pp. 66-67; DOMÍNGUEZ, Olivia, "Del sueño regional a la experiencia nacional. La Liga de Comunidades Agrarias de Veracruz", SANDOVAL, Roberto, "La Liga de Comunidades Agrarias del Estado de Veracruz. Su contribución al pensamiento agrario de México" y RONZÓN, José, "Un intento de campaña. Los tejedistas ante la sucesión presidencial de 1934" en DOMÍNGUEZ, Olivia (Coord.), Agraristas y agrarismo. La Liga de Comunidades Agrarias del Estado de Veracruz, México, Consejo Técnico Consultivo de la LCA y SCEV, Gobierno del Estado de Veracruz, 1996, pp. 31, 35, 55, 92-93. Tejeda no participó en la creación de la estructura partidista estatal del PNR por considerar que la nueva organización era "demasiado burocrática". La desarticulación del movimiento agrario veracruzano y la promulgación de la ley de patrimonio ejidal en noviembre de 1932, misma que planteó la organización comunal obligatoria para los ejidos y al mismo tiempo permitió desarticular las guerrillas campesinas veracruzanas, constituyeron dos estrategias políticas tendientes a eliminar las bases de apoyo a Tejeda, quien aspiraba a convertirse en candidato presidencial en 1934. De hecho, Otero plantea que la elección de Cárdenas buscaba, entre otras cosas, contrarrestar las presiones del tejedismo "radical". Por este motivo, Tejeda decidió abandonar el PNR y aceptó la postulación del Partido Socialista de las Izquierdas, situación que aceleró las presiones y el acoso hacia los tejedistas.
} 
la delegación del DA, que la dimisión de los dos personajes estaba justificada, pues eran partidarios del profesor Enrique López Huitrón, quien abandonó su cargo de inspector técnico escolar para tratar de obtener una diputación local. A este personaje se le conocía por ser un "agitador" y por tratar de desarticular a las masas campesinas. Sumado a esto, se debía tener en cuenta que la directiva había cumplido su período, motivo por el cual era necesario realizar una nueva elección que promoviera la unión de los ejidatarios, ya que los anteriores dirigentes habían abusado de sus atribuciones. La petición de Moreno fue avalada por la delegación de la CNA; se realizó el nombramiento del nuevo CE cuya presidencia recayó en Francisco Velasco. Esta situación coyuntural fue aprovechada por un grupo de campesinos que pidieron a Moreno, el 12 de diciembre de 1937, que integrara un terreno perteneciente a la hacienda de "La Victoria" al proyecto de dotación de Catemaco, solicitud que se sustentaba en el hecho de que lo arrendaban y colindaba con la población. Empero, su propuesta no procedión ${ }^{37}$.

\section{El fortalecimiento del Comisariado Ejidal}

El 21 de marzo de 1938, Francisco Velasco pidió la entrega de los predios Zanja Honda, Chalchoapan y Matacapan, petición que, según el dirigente, fue avalada por el jefe de la brigada de ingenieros, Luis Briones. Por este motivo, el DA pidió al ingeniero Santiago Góngora que realizara una inspección de los terrenos; este informó que los terrenos mencionados eran excedentes del ejido de Maxacapan. Los ejidatarios de Catemaco los solicitaron en arrendamiento, pero el presidente municipal de Maxacapan no lo autorizó, por lo cual decidieron tomar posesión de las tierras pese a la oposición del CE de Maxacapan, mismo que incitó a un grupo de ejidatarios para ocuparlas. Ante tal hecho, Luis Briones ordenó a Ramón Vázquez, el 2 de abril de 1938, que realizara un nuevo censo y que analizara la posibilidad de ampliar el ejido. Esta medida no fue bien recibida por Trinidad G., Marcelino Absalón Pérez, Juan Leal Zárate y Guillermo J. Álvarez, quienes solicitaron a la CAM que no se afectaran sus propiedades. Aunque se les advirtió que sus tierras se encontraban fuera del área a expropiar, lo cierto es que las posesiones de los dos últimos fueron ocupadas por los ejidatarios y solo lograron su devolución tras la presentación de las respectivas escrituras. Con la intención de evitar que se repitiera la experiencia, Góngora pidió a Briones que se le remitiera una lista de los 759 lotes de diez hectáreas que circundaban a Catemaco, a fin de determinar cuáles podían ser aprovechados para la dotación y así no incurrir en "invasiones involuntarias". No obstante, Góngora no cumplió con la encomienda por causa de las quejas del CE en su contra, de modo que se pidió que los ingenieros Roberto Velázquez y Fernando Bruixola asumieran esa tarea ${ }^{38}$.

Durante el levantamiento del censo, un grupo de vecinos de Catemaco solicitó a Luis Briones que se les considerara ejidatarios de Coetzalapan, acción que evidenciaba la persistencia de las pugnas entre los campesinos. Ellos, además, pidieron que sus

\footnotetext{
${ }^{37}$ AGEV. CAM, Catemaco, caja 101, exp. 152, ff. 597, 603, 610, 612-615.

${ }^{38}$ AGEV. CAM, Catemaco, caja 101, exp. 152, ff. 630, 633-635, 638, 641-642, 647-650, 652-655, 657-658.
} 
propiedades se anexaran a la población mencionada, petición que fue rechazada por las autoridades agrarias. El 5 de diciembre de 1938 Velázquez informó que en Catemaco había 4621 personas de las cuales 932 tenían derecho a dotación, aunque aclaraba que algunos se dedicaban a la pesca, al comercio y a labores diversas. Ante los rumores relativos a que Alberto Turrent buscaba recuperar su predio Olotepec y por carecerse de ingenieros, Briones pidió a Góngora, el 1 de abril de 1939, que volviera a hacerse cargo del proyecto de dotación. La designación no agradó al CE y en cuanto se presentó la oportunidad lo acusaron por la mala relación que mantenía con los trabajadores, por pedir que se le pagaran sus alimentos y por trabajar a intervalos con la intención, según el CE, de permitir que los terratenientes fraccionaran sus terrenos para que no se les pudiera afectar. Por los anteriores motivos, el CE pidió que se asignara a otro ingeniero. La solicitud no tuvo respuesta aun cuando el ingeniero Ramón Plascencia corroboró las afirmaciones de los ejidatarios, además de que se demostró que Góngora no cumplió con las tareas asignadas. Pese a las acusaciones, la CAM mantuvo al ingeniero en Catemaco y solo se limitó a pedirle que acelerara los trabajos. Góngora entregó un informe incompleto y carente de la información relativa a los terrenos de Matacapan, debido a que, según el ingeniero, el representante de Luis Carrión impidió que hiciera su medición ${ }^{39}$.

La coerción ejercida sobre el ingeniero no resultó un episodio aislado, por el contrario, evidenciaba la posición de un CE que trataba de afianzar su poder en el interior del ejido, de manera que, por ejemplo, el 5 de julio de 1939 separó a Nicolás Moreno de la presidencia del Consejo de Vigilancia con el argumento de haber quemado unos árboles para vender el carbón a Eugenio Turrent. Cuatro días después, el CE exigió a Rafael Cárdenas, Manuel Álvarez, Crispín Pizano, Manuel Escobar Azamar, Rafael Zacarías e Hilario Toto que desocuparan sus predios. Las acciones arbitrarias en las que incurría el CE generaron la molestia de los ejidatarios, quienes pidieron, el 3 de septiembre de 1940, que se efectuaran elecciones para cambiar la directiva, pero su petición no obtuvo respuesta del DA. El 26 de mayo de 1941, el CE notificó al gobernador que por órdenes de Salvador Oliveros, presidente municipal de San Andrés Tuxtla, el comandante de policía buscó reemplazarlo, hecho que demostraba, según ellos, que Oliveros era "un enemigo de las organizaciones agrarias". Este desmintió la versión, decía que no tenía la intención de "actuar como gendarme" y que carecía de facultades para realizar cambios en la directiva ejidal. Sin embargo, Oliveros aclaró que el CE estaba influenciado por Encarnación Domínguez y Juan Anota, este último era el líder de la CTM en la región, quienes no eran ejidatarios y presionaban a Felipe Domínguez para que no acatara el fallo resolutivo. Para evitar la coerción, Domínguez cerró la oficina en la que sesionaba y solicitó el auxilio del Ayuntamiento, mientras las autoridades agrarias resolvían el problema. Oliveros indicaba que el recinto fue tomado por los "elementos desafectos" y si ellos no los desalojaron, se debía a que no buscaban que se produjera un enfrentamiento entre los grupos.

${ }^{39}$ AGEV. CAM, Catemaco, caja 101, exp. 152, ff. 148-294, 660-661, 664, 666, 670-683, 686, 689, 693-694, 697-698, 700-701, 703, 714, 718. 
El munícipe acusó a Encarnación Domínguez y a Juan Anota de haber sido los artífices de la denuncia, por tal razón aclaró que no se le debía considerar un "enemigo de los campesinos". Felipe Domínguez corroboró que la acusación en contra de Oliveros era falsa y había sido promovida por Juan Anota para "sembrar el desorden" entre los ejidatarios. Las anteriores declaraciones mostraban el enfrentamiento que existía entre la autoridad ejidal, que era apoyada por la presidencia municipal, y la CTM. Es evidente que el autor de la denuncia buscaba desestabilizar la relación que existía entre el CE y la presidencia municipal. Las arbitrariedades que realizaba el CE provocaron que algunos de los campesinos buscaran cambiar su lugar de residencia, tal como sucedió con Francisco Martínez que solicitó autorización para vender su propiedad, pues decía que la autoridad ejidal redujo su parcela y le exigió el pago de 20 pesos para trabajarla. El querellante no vendió su propiedad sino que se la transfirió a su hijo Antonio, que también sufrió el hostigamiento del comisariado que le exigió el mismo pago, situación que provocó la indignación de Francisco, que informó del asunto al delegado de Promoción Ejidal, sin que lograra obtener una respuesta ${ }^{40}$.

\section{Violencia contra los ejidatarios de Catemaco}

El constante enfrentamiento entre Catemaco y Maxacapan por el establecimiento de los límites ejidales tomaría un giro inesperado el 17 de noviembre de 1941, día en el que el ingeniero Ramón Plascencia se presentó en Catemaco acompañado de un piquete de soldados y de un grupo de campesinos de Maxacapan, a quienes les prometió la entrega de unas hectáreas que formaban parte del ejido provisional de Catemaco. Como el CE se opuso a la operación, el ingeniero los amenazó y les pidió a los soldados que los amedrentaran. Al día siguiente, un grupo de ejidatarios que se dirigía a San Andrés Tuxtla fueron baleados por unos militares que se encontraban escondidos en la carretera. En la acción resultaron heridos Pablo Claudio Domínguez y Manuel Escobar. Por tal motivo, el CE pidió que se investigaran las "perversas maniobras" del ingeniero, con la intención de desaforarlo de manera inmediata y de ese modo poder enjuiciarlo por la agresión contra los ejidatarios. ${ }^{41}$ Ellos afirmaban que Plascencia no los apoyaba, aunque se le proporcionó alimentación para que culminara los trabajos. Su lentitud se explicaba, según el $\mathrm{CE}$, por el hecho de que recibió dinero de Luis Carrión y Alberto Turrent. Esta no sería la primera ocasión en la que se denunció a Plascencia por apoyar a los terratenientes, puesto que unos meses antes el CE acusó al ingeniero de ser un "chanchullero", un "borracho" y de haber recibido dinero para no incluir los predios Matacapan, Plan de Chilapa y Olotepec en el proyecto de dotación. El ataque contra los ejidatarios provocó la reacción del CE

\footnotetext{
${ }^{40}$ AGEV. CAM, Catemaco, caja 101, exp. 152, ff. 726, 732-733, 735-736, 759.

${ }^{41}$ MEYER, Lorenzo, El conflicto, pp. 278-281. Es probable que Plascencia hubiera actuado de esa manera, debido a que, desde 1932, la presidencia de la república había ordenado que los ingenieros destacados en Veracruz contaran con el apoyo del ejército, cuando consideraran que las circunstancias no los favorecían. Esta disposición fue consecuencia de un enfrentamiento generado entre los ejidatarios de Tirrea Colorada, Loma de Nanche y Plan de Manantiales, quienes se negaron a aceptar las dotaciones propuestas por los ingenieros. La instrucción también tenía el objetivo de buscar el desarme de las guerrillas campesinas que apoyaban el proyecto agrarista de Tejeda.
} 
de Comoapan, una población vecina a Catemaco, corroborando como el ingeniero hostigaba a los campesinos y trataba de asesinarlos para quitarles sus propiedades ${ }^{42}$.

Los de Comoapan no solo pidieron el desafuero de Plascencia sino que se le expulsara de Los Tuxtlas, porque era un "borracho" que trataba de perjudicar a las organizaciones campesinas de la región. Ellos advertían que el ingeniero no comulgaba con los "intereses de los campesinos" y se mostraba como un denodado defensor de los terratenientes. Es importante mencionar que la denuncia del CE de Comoapan fue enviada el 19 de enero de 1942, es decir, dos meses después de la confrontación. En ella existían algunos datos erróneos como la fecha y el lugar en que se produjo el incidente, pues se indicaba que fue el 17 de enero de 1942 en Maxacapan. Aunque es difícil explicar las equivocaciones presentes en la carta de los de Comoapan, lo cierto es que estos decidieron respaldar a los de Catemaco, ya que también habían tenido problemas con el ingeniero ${ }^{43}$. Las autoridades agrarias no tuvieron en cuenta las protestas de los dos CE y Plascencia permaneció en la región, aun cuando se le presentaron otras acusaciones, tales como la de Luz Fonseca, quien decía que el ingeniero trató de quitarle una propiedad de ocho hectáreas que ella ocupaba por más de 20 años, o la que realizó el CE de Santiago Tuxtla, que indicó que el ingeniero buscaba favorecer a los ejidatarios de una población colindante ${ }^{44}$. Con la intención de poner punto final a los conflictos en Catemaco, el 25 de abril de 1942, el delegado del DA dio posesión parcial definitiva de 3 740-10 hectáreas, que se tomaron del predio Olotepec de la testamentaria de Alberto Turrent (1 827-50), de la hacienda Sontecomapan del gobierno federal (1 000), del predio Chalchoapan de la testamentaria de Octaviano Carrión (423), del predio Boca del Monte de Manuel Turrent (170), de la Compañía de Tabacos de San Andrés (114), de la hacienda Matacapan de Matilde Rosa Carrión (108-60) y del predio Pipiapan de Maria Luisa Carrión (29). A pesar de que los Turrent habían sido los más afectados, ello no constituyó un impedimento para que realizaran una donación de 68 hectáreas para la comunidad ${ }^{45}$.

Como se estipuló que la dotación era parcial, los de Catemaco presionaron a las autoridades agrarias para que se tomaran los terrenos faltantes de uno de los predios de la testamentaria de Octaviano Carrión. La propuesta no agradó a un grupo de campesinos, encabezados por José Ramírez y Benito Pascual, quienes indicaron a la CAM, el 17 de noviembre de 1943, que no existían razones válidas para entregar las tierras solicitadas pues se encontraban a 20 kilómetros del ejido, no pertenecían a Carrión sino que fueron embargados a Tiburcio Sánchez, y ellos las habían ocupado en vista de que estaban abandonadas ${ }^{46}$.

\footnotetext{
${ }^{42}$ AGEV. CAM, Catemaco, caja 101, exp. 152, f. 717, 740.

${ }^{43}$ AGEV. CAM, Comoapan, caja 240, exp. 629, s.f.; AGEV. CAM, Santiago Tuxtla, caja 161a, exp. 332, ff. 177-178. Una queja similar fue manifestada por el CE de Santiago en 1939.

${ }^{44}$ AGEV. CAM, Santiago Tuxtla, caja 161a, exp. 332, ff. 165-167, 175-178, 180-181.

${ }^{45}$ AGEV. CAM, Catemaco, caja 101, exp. 152, ff. 721-722, 741, 760-761; AGEV. CAM, Comoapan, caja 240, exp. 629, s.f.

${ }^{46}$ AGEV. CAM, Catemaco, caja 101, exp. 152, ff. 765-767, 775-777.
} 


\section{División del ejido y pugnas entre los grupos ejidales}

En abril de 1945 volvieron a aflorar los problemas de límites entre Catemaco y Maxacapan. El CE del primero notificó que algunos vecinos de Maxacapan se habían instalado en el punto conocido como "Cabeza de basura", lugar en el que construyeron tres casas de zacate y cuando se les pidió que desalojaran las tierras, ellos alegaron que la CAM autorizó su ocupación. Como los de Catemaco no creían en la validez del argumento, pidieron que el DA interviniera para evitar mayores dificultades. En respuesta, el DA informó que se realizaría el deslinde del ejido, pero el CE pidió que lo hiciera la jefatura de la brigada agraria pues no confiaba en el trabajo de los ingenieros adscritos a la región. Sin embargo, la jefatura se deslindó del problema con el pretexto de que carecía de personal. A raíz de que la tesorería municipal envió un requerimiento al CE para que pagara las deudas atrasadas, un grupo de campesinos aprovechó la ocasión para denunciar a la directiva, el 15 de noviembre de 1947, ante la organización agraria ejidal, decían que funcionaba sin nombramiento desde 1944, no había cubierto las contribuciones a pesar de que los ejidatarios las pagaban con puntualidad y vendía los árboles del ejido sin dar cuenta de las ganancias que se obtenían. Ante estas condiciones, pedían que el jefe de promoción ejidal se trasladara a Catemaco para realizar el cambio de la dirigencia. Aunque los campesinos exageraban en la cantidad que el CE debía por concepto de contribuciones, la suma ascendía a 691 pesos, en lo que sí tenían razón era en la ilegalidad de su funcionamiento, puesto que no se habían realizado elecciones para cambiar la mesa directiva, esta seguía en funciones y debía dejar el cargo desde enero de ese año. Ante la continua invasión del ejido de Catemaco por parte de Maxacapan, el presidente de la república decretó el 20 de septiembre de 1950 que Catemaco se dividiera en dos núcleos: al primero le corresponderían 7110 hectáreas con 811 ejidatarios, mientras que al segundo se le otorgarían 578 hectáreas con 60 ejidatarios, de las cuales se destinarían 25 para la zona urbana ${ }^{47}$.

El ingeniero Manuel Jáquez realizó la división el 29 de noviembre de 1950 y al nuevo núcleo de población se le otorgó el nombre de "Licenciado Mario Sousa". Como la población de Coyame pidió a la CAM, en julio de 1951, que se le diera dotación de tierras, los ejidatarios de Catemaco solicitaron que se concluyera el deslinde de sus tierras, petición que ocasionó la airada protesta de los de Coyame, quienes argumentaban que se les quitaban los terrenos que pidieron. Esta acusación no estaba alejada de la realidad, dado que los de Catemaco procedieron a la invasión de las propiedades cercanas a los linderos de Coyame. Las acciones del CE, cuyo presidente era Adolfo Hernández, no fueron aprobadas por un grupo de ejidatarios encabezados por Nicolás Moreno, ellos pidieron, en agosto de 1952, que se realizara un cambio de directiva, ya que según Moreno, el CE no había pagado los impuestos y las cuotas extraordinarias. El CE acusó a Moreno de rebeldía ante la Asamblea General, en la que estuvieron presentes el presidente municipal de Catemaco y el secretario general de la LCA, personajes llamados por Hernández para darle "seriedad al asunto". Como el CE contaba con el apoyo de las dos autoridades, la petición de Moreno fue rechazada

$\overline{{ }^{47} \text { AGEV. CAM, Catemaco, caja 101 }}$, exp. 152, legajo 101, f. 770, 778-780, 783, 785, 829. 
pues se decía que actuaba bajo la influencia de "políticos agitadores", además, se ratificó la continuidad de la directiva, afirmaban que el presidente y el secretario no se podía dejar que el CE quedara en manos de elementos "irresponsables" que se oponían al "mejoramiento colectivo", porque podría ocasionar que la autoridad ejidal se sustrajera de la influencia de la LCA, y esto representaba el incumplimiento del "programa del gobernador" en materia agraria ${ }^{48}$.

Este hecho resulta interesante por varias razones: en primer lugar, no se consultó a las autoridades agrarias respecto a las posibilidades de realizar el cambio o no; en segundo lugar, se descubría la estrecha relación que el CE había establecido con la presidencia municipal y con la LCA; en tercer lugar, se presentaba el asunto como un enfrentamiento entre grupos políticos; en cuarto lugar, se observaba la capacidad política de Hernández para desvirtuar el argumento de su enemigo; y en quinto lugar, se justificaba la continuidad del CE como una forma de defender un proyecto estatal que implicaba la incorporación de las organizaciones campesinas al modelo corporativista que sustentaba el partido gobernante a nivel nacional, así como un respeto a la propiedad privada de la tierra con la intención de acelerar el crecimiento económico en el Estado ${ }^{49}$. Para refrendar su triunfo, el CE procedió a despojar de sus parcelas a varios de los que lo habían acusado. Esta práctica punitiva fue común en la región, lo mismo ocurrió con el CE de Santiago Tuxtla que procedió de esa forma en varias ocasiones ${ }^{50}$. Pese a las quejas de los afectados, el DA se limitó a informarles que investigaría el asunto. En tanto que el CE continuó con el despojo de parcelas, un grupo de campesinos solicitó, el 13 de marzo de 1953, que se hiciera la substitución de la directiva. Como la autoridad federal guardó silencio, el CE prosiguió con sus acciones arbitrarias ante la impotencia de los ejidatarios, tal como se observa en el caso de Teodosio Martínez quien denunció penalmente a Adolfo Hernández por injurias. El juzgado de primera instancia dictó auto de formal prisión en su contra, pero Hernández logró salir bajo fianza y ordenó que se le quitara su parcela, hecho que provocó la intervención del jefe de promoción ejidal Agustín Pesado, sin que se obtuviera algún resultado favorable al querellante, por lo cual Martínez pidió que el DA tomara cartas en el asunto, pues no podía entender las razones por las cuales un hombre procesado continuaba al frente del $\mathrm{CE}^{51}$.

El 27 de octubre de 1953, un grupo de campesinos solicitó que no solo realizara el cambio de la directiva del CE, sino también la del jefe de promoción ejidal. Finalmente, en diciembre de ese año se realizaron elecciones en las que resultó triunfador Juan Hernández, pero, al igual que su antecesor, se le acusó de quitarle la tierra a los ejidatarios que no lo apoyaron. Gracias a la cooptación de los ejidatarios, Hernández consiguió mantener el control del ejido durante varios años. La forma en la que actuaba el CE provocó que Agustín Ortega, quien fungía como secretario general del Comité Regional Campesino, el 5 de octubre de 1954, solicitara al

\footnotetext{
${ }^{48}$ AGEV. CAM, Catemaco, caja 101, exp. 153, ff. 790-791, 793, 796-798, 800, 802, 804.

${ }^{49}$ BLÁZQUEZ, Carmen, Op. Cit., pp. 194-195.

${ }^{50}$ AGEV. CAM, Santiago Tuxtla, caja 161a, exp. 332, ff. 161-162, 165.

${ }^{51}$ AGEV. CAM, Catemaco, caja 101, exp. 153, ff. 798, 800, 802, 804, 810, 813, 815-816, 817-818, 820.
} 
delegado del DA dictar disposiciones severas para castigar a las autoridades ejidales violadoras de los derechos de los campesinos. Ortega afirmaba que como los Comisariados Ejidales contaban con el apoyo de los jefes de zona ejidal, se sentían "omnímodos" e impedían llevar a cabo las disposiciones federales en materia agraria. La petición de Ortega no encontró respuesta, como sucedía en el caso de Catemaco, el CE actuaba bajo sus propias reglas. Por ejemplo, en 1957 no permitió celebrar las elecciones para cambiar la directiva y en 1958 autorizó la invasión de la pequeña propiedad de Dolores Cinta, misma que colindaba con el ejido. Estos actos fueron denunciados por los campesinos y la propietaria, pero las respuestas de las autoridades agrarias fueron cautelosas y sin compromiso. Resulta interesante mencionar que los de Catemaco se quejaban cuando otros campesinos ocupaban sus tierras, pero si ellos lo hacían se justificaban con el argumento de seguir los lineamientos estipulados en el plano formado en 1942. Los problemas de ocupación de las tierras colindantes continuarían en la década de 1960, asunto que, por su propia dinámica, será explorado en un trabajo posterior, pero que da cuenta de la complicada situación interna de los ejidatarios y sus colindantes ${ }^{52}$.

\section{Conclusión}

El caso de Catemaco resulta significativo por la intensa lucha de intereses registrados en la comunidad campesina y en la que estuvieron involucrados diversos actores políticos. En Catemaco no se logró conformar un poderoso CE, tal como ocurrió en la vecina población de Santiago Tuxtla en donde dicho organismo logró regir los destinos del ejido por 15 años, un objeto de disputa de las diversas facciones. Este hecho muestra, como lo han advertido varios autores, que los campesinos no formaban un ente homogéneo, sino que cambiaban sus lealtades de acuerdo a sus intereses ${ }^{53}$. A fin de fortalecer su posición, el CE de Catemaco estableció un fuerte vínculo con el Ayuntamiento y con la LCA, relación que le permitió sobrevivir a los ataques de otros organismos campesinos y a la presión ejercida sobre los ejidatarios inconformes. Sin embargo, la relación del CE con los diversos actores políticos se modificaría de acuerdo a las circunstancias a nivel estatal, ello se puede apreciar en su pugna con la CTM o su incorporación al proyecto político del PNR.

Es evidente que los principales beneficiarios de la reforma no fueron los ejidatarios, sino los diversos dirigentes del CE, condición que no solo fue privativa de Catemaco, también en Santiago Tuxtla. La presencia de estos liderazgos locales, aunque de carácter efímero, se explicaba en función de que el tejedismo promovió su aparición y les permitió, en muchas ocasiones, incurrir en prácticas abusivas sin el temor de ser reprimidos. Así, las autoridades ejidales se convirtieron, gracias a las leyes agrarias,

\footnotetext{
${ }_{52}^{52}$ AGEV. CAM, Catemaco, caja 101, exp. 153, ff. 824, 832, 855-857, 862, 865, 867, 879.

${ }^{53}$ NÚÑ̃E, María Cristina, Ejido, Caña y Café. Política y cultura campesina en el centro de Veracruz, México, Universidad Veracruzana, 2005, pp. 36, 94; SKERRIT, David, "Un estudio de caso en el agrarismo de Veracruz. Puente Nacional”, en DOMÍNGUEZ, Olivia (Coord.). p. 224; BAINTENMANN, Helga, "Reforma agraria y ciudadanía...", Op. cit., pp. 72, 77.
} 
en una estructura de gobierno paralela, debido a que controlaban las formas locales de gobierno, los servicios públicos y sobre todo, las tierras otorgadas en dotación.

Otro aspecto interesante es el papel jugado por los ingenieros encargados de realizar los proyectos de dotación, dado que, tanto Góngora como Plascencia, buscaron interponer sus intereses sobre los de la comunidad, realidad particular del caso de Catemaco, ya que en las otras poblaciones de Los Tuxtlas no se presentaron casos de intervencionismo de los ingenieros. A pesar de comprobarse que el primero incurría en actos de corrupción, la autoridad agraria solo se limitó a removerlo de su puesto y por absurdo que parezca, después lo volvió a reinstalar en sus funciones aun cuando volvió a reincidir en las mismas prácticas. Los vínculos que Plascencia estableció con algunos de los grandes propietarios pueden ayudar a explicar sus acciones, pues resulta incongruente que un ingeniero encargado de resolver los problemas de los campesinos de la localidad fuera el primero en atacarlos de manera deliberada. La información no muestra que hayan existido fricciones previas entre Plascencia y los campesinos de Catemaco. Es cierto que estos se negaron a cumplir una orden a vista de ellos ilegal, pero este argumento no bastaba para que fueran agredidos con armas de fuego. Las autoridades agrarias, tanto federales como estatales, no ordenaron abrir una investigación para deslindar responsabilidades. Este caso resulta inédito porque ataques contra campesinos encabezados por un ingeniero no se registraron en las poblaciones vecinas, lo cual abre una línea de investigación historiográfica respecto al papel jugado por estos hombres en los procesos de reforma agraria, a nivel local y regional.

Un tercer asunto a destacar es la confrontación surgida entre Maxacapan y Catemaco a causa de los límites de sus respectivos ejidos, contexto que también vivieron otras comunidades de la región, en buena medida por la superposición de los proyectos de dotación, este problema fue provocado por los inconvenientes que los ingenieros enfrentaban para delimitar la tierra, la tardanza de las autoridades ejidales para emitir un dictamen y la constante petición de tierras de los núcleos agrarios. La resolución del gobierno federal de dividir el ejido de Catemaco no resultaría adecuada, pues el CE de esta población, en compensación, buscó apropiarse de las tierras que se le iban a otorgar a los de Coyame. Lo anterior evidencia que el propósito de las autoridades agrarias no se cumplió, dado que se trató de evitar un enfrentamiento, pero se pusieron las bases para generar otro, cuyos únicos beneficiarios fueron los líderes campesinos. Las tensiones existentes, tanto al interior como el exterior del ejido, muestran que por lo menos en el caso de Catemaco, el proceso de reforma agraria fue conflictivo y que los actores sociales no siempre seguían los mismos objetivos, aunque en el discurso se esbozaba la idea de buscar la "felicidad" del campesinado. Lo precedente confirma que no se puede considerar al campesinado como un grupo homogéneo que buscaba conseguir fines comunes, por el contrario, cada quien buscaba obtener beneficios particulares que, en muchas ocasiones, podían afectar a los otros. En este sentido, Catemaco resulta un caso de interés, que pone en evidencia las tensiones internas y externas que afectaban la dinámica de la población. 


\section{Fuentes}

\section{Fuentes primarias}

\section{Archivos}

Archivo General del Estado de Veracruz, Comisión Agraria Mixta

Archivo Municipal de Jalapa. Actas de Cabildo

Acervo Histórico de Notarías del Distrito Federal

The Nettie Lee Benson Latin American Collection. Archivo de Lucas Alamán

\section{Fuentes Secundarias}

\section{Libros}

BLÁZQUEZ, Carmen, Breve historia de Veracruz, FCE, El Colegio de México, Fideicomiso Historia de las Américas, México, 2000.

BLÁZQUEZ, Carmen y CORZO, Ricardo (Coords.), Colección de Leyes y Decretos de Veracruz, México, Universidad Veracruzana, 1997, tomo I (1824-1827), tomo III (1840-1860), tomo VI (1874-1879), tomo VII (1880-1883), tomo VIII (1884-1886), tomo IX (1887-1890).

DULLES, John, Ayer en México. Una crónica de la Revolución (1919-1936), México, FCE, 1989.

FALCÓN, Romana, El agrarismo en Veracruz. La etapa radical (1928-1935), México, El Colegio de México, 1977.

FALCÓN, Romana y GARCÍA, Soledad, La semilla en el surco. Adalberto Tejeda y el radicalismo en Veracruz, 1883-1960, México, El Colegio de México, Gobierno del Estado de Veracruz, 1986.

GARCÍA, Bernardo, El Marquesado del Valle. Tres siglos de régimen señorial en Nueva España, México, El Colegio de México, 1969.

GONZÁLEZ, José, Los Tuxtlas, Archivo General del Estado de Veracruz, Jalapa, 1991.

HERRERA, Salvador, Entre la magia y la bruma. Estampas catemaqueñas, México, Instituto Veracruzano de Cultura, 2007.

IGLESIAS, José María, Acayucan en 1831, México, Editorial Citlaltepetl.

MALDONADO, Serafín, De Tejeda a Cárdenas. El movimiento agrarista de la revolución Mexicana, 1920-1934, México, Editorial Universitaria de Guadalajara, 1992. 
MEDEL, León, Historia de San Andrés Tuxtla, 1525-1912, México, editorial Citlaltépetl, 1993.

MEYER, Lorenzo, Historia de la Revolución Mexicana. 1928-1934. El conflicto social y los gobiernos del Maximato, tomo 13, México, El Colegio de México, 2000.

MEYER, Lorenzo, SEGOVIA, Rafael y LAJOUS, Alejandra, Historia de la Revolución Mexicana. 1928-1934. Los inicios de la institucionalización, tomo 12 , México, El Colegio de México, 1981.

NÚÑEZ, María Cristina, Ejido, caña y café. Política y cultura campesina en el centro de Veracruz, México, Universidad Veracruzana, 2005.

OLAVARRIETA, Marcela, Magia en Los Tuxtlas, Veracruz, México, Instituto Nacional Indigenista, CONACULTA, 1990.

OTERO, Gerardo, ¿Adiós al campesinado? Democracia y formación política de las clase en el México rural, México, Universidad Autónoma de Zacatecas, Simon Frazer University, Miguel Ángel Porrúa editor, 2004.

SOLÍS, Ruth (Comp.), Veracruz en el Diccionario Universal de Historia y Geografía, 1853-1856, México, Gobierno del Estado de Veracruz, Secretaria de Educación y Cultura, 1998.

SOUTHWORTH, J. R., Veracruz Ilustrado, México, Editora de Gobierno del Estado de Veracruz, 2005.

VELASCO, José, El péndulo de la resistencia (La defensa de la territorialidad y la autonomía indígena), México, Gobierno del Estado de Veracruz, 2002.

\section{Capítulos de libros}

BAITENMANN, Helga, "Reforma agraria y ciudadanía en el México del siglo XX", en GÓMEZ, Francisco Javier, Paisajes mexicanos de la reforma agraria. Homenaje a William Roseberry, México, El Colegio de Michoacán, BUAP, 2007, pp. 71-95.

DE MEDINA, Juan, "Relación de Tlacotalpan y su partido", en ACUÑA, René (Ed.), Relaciones geográficas del siglo XVI: Tlaxcala, México, UNAM, 1985, pp. 279-297.

DEL REY POVEDA, Alberto y QUESNEL, André, "Las implicaciones intrafamiliares, intergeneracionales y migratorias de la política agraria en México. El caso del sur del estado de Veracruz, México", en Ulúa. Revista de Historia, Sociedad y Cultura, año 5, No. 9, México, Universidad Veracruzana, enero-junio de 2007, pp. 59-86.

DOMÍNGUEZ, Olivia, "Del sueño regional a la experiencia nacional. La Liga de Comunidades Agrarias de Veracruz", en DOMÍNGUEZ, Olivia (Coord.), Agraristas 
y agrarismo. La Liga de Comunidades Agrarias del Estado de Veracruz, México, Consejo Técnico Consultivo de la LCA y SCEV, Gobierno del Estado de Veracruz, 1996, pp. 19-37.

ESCOBAR, Antonio y GUTIÉRREZ, Ana María, "Dos momentos del proceso agrario veracruzano: el caso de Chicontepec", en Estudios campesinos en el Archivo General Agrario, volumen II, México, RAN, CIESAS, CONACYT, 1999, pp. 205-209.

GINZBERG, Eitan, "Formación de la infraestructura política para una reforma agraria radical: Adalberto Tejeda y la cuestión municipal en Veracruz, 1928-1932”, en GARCÍA, Bernardo y SKERRIT, David (Eds.), La Revolución Mexicana en Veracruz. Antología, México, Gobierno del Estado de Veracruz, Secretaria de Educación de Veracruz, 2009, pp. 381-441.

KOURÍ, Emilio, "Economía y comunidad en Papantla: reflexiones sobre la cuestión de la tierra en el siglo XIX", en ESCOBAR, Antonio y ROJAS, Teresa (Coords.), Estructuras y formas agrarias en México. Del pasado al presente, 199-214, México, CIESAS, SRA, CONACYT, Universidad de Quintana Roo, 2001, pp. 199-214.

LÉONARD, Eric y VELÁZQUEZ, Emilia, "El reparto agrario y el fraccionamiento de los territorios comunitarios en el sotavento veracruzano: construcción local del Estado e impugnación del proyecto comunal”, en VELÁZQUEZ, Emilia, et al., El Istmo mexicano: una región inasequible. Estado, poderes locales y dinámicas espaciales (Siglos XVI-XXI), México, CIESAS, IRD, 2009, pp. 399-454.

REMY, H., "Tierra Caliente. Impresiones en México", en Cien viajeros en Veracruz. Crónicas y relatos. 1856-1874, tomo VI, México, Gobierno del Estado de Veracruz, 1992, pp. 49-71.

RONZÓN, José, "Un intento de campaña. Los tejedistas ante la sucesión presidencial de 1934", en DOMÍNGUEZ, Olivia (Coord.), Agraristas y agrarismo. La Liga de Comunidades Agrarias del Estado de Veracruz, México, Consejo Técnico Consultivo de la LCA y SCEV, Gobierno del Estado de Veracruz, 1996, pp. 79-107.

SANDOVAL, Roberto, "La Liga de Comunidades Agrarias del Estado de Veracruz. Su contribución al pensamiento agrario de México", en DOMÍNGUEZ, Olivia (Coord.), Agraristas y agrarismo. La Liga de Comunidades Agrarias del Estado de Veracruz, México, Consejo Técnico Consultivo de la LCA y SCEV, Gobierno del Estado de Veracruz, 1996, pp. 39-63.

SKERRIT, David, "Un estudio de caso en el agrarismo de Veracruz. Puente Nacional", en DOMÍNGUEZ, Olivia (Coord.), Agraristas y agrarismo. La Liga de Comunidades Agrarias del Estado de Veracruz, México, Consejo Técnico Consultivo de la LCA y SCEV, Gobierno del Estado de Veracruz, 1996, pp. 211-230. 


\section{Artículos}

GÓMEZ, Laura Guillermina, "Legislación e instituciones agrarias en México, 19111924" en Anuario Colombiano de Historia Social y de la Cultura, vol. 40, No. 1, Bogotá, Universidad Nacional de Colombia, enero-junio de 2013, pp. 273-297.

JIMÉNEZ, Rogelio, “Campesinos contra campesinos: conflictos agrarios y lucha por la tierra en Comoapan, Veracruz. (1925-1942)" en Anuario de Historia Regional y de las Fronteras, vol. 18, No. 2, Bucaramanga, Universidad Industrial de Santander, diciembre de 2013, pp. 355-382.

JIMÉNEZ, Rogelio, "El proceso de reparto de la propiedad comunal en dos poblaciones del Cantón de los Tuxtlas, Veracruz durante la década de 1880" en Memoria y Sociedad, vol. 14, No. 29, Bogotá, Pontificia Universidad Javeriana, juliodiciembre de 2010, pp. 107-124.

LÉONARD, Eric, “Avatares y descarrilamiento del proyecto agrario liberal. Disolución de la propiedad comunal y modernización agrícola en los Tuxtlas, 1880-1910”, en Ulúa. Revista de Historia, Sociedad y Cultura, año 5, No. 9, México, Universidad Veracruzana, enero-junio de 2007, pp. 9-58.

VELASCO, José y SANTOS, Lucía, "La reforma agraria en el municipio de Cosamaloapan, Veracruz (México), 1915-1945" en Anuario de Historia Regional y de las Fronteras, vol. 19, No. 2, Bucaramanga, Universidad Industrial de Santander, 2014, pp. 451-477.

VARGAS, Guadalupe, "Prácticas religiosas y New Age en Los Tuxtlas, Veracruz" en Contrapunto, vol. 4, No. 12, México, Editora del Gobierno del Estado de Veracruz, septiembre-diciembre de 2009, pp. 64-72.

\section{Tesis}

BAINTEMANN, Helga, "Rural Agency and State Formation in Postrevolutionary Mexico: The Agrarias Reforma In Central Veracruz (1915-1992)", tesis para obtener el grado de Doctora en Filosofía, Ann Arbor, New School for Social Research, 1997. 